\title{
1 Innovative TEM-coupled approaches to study foraminiferal cells
}

2

3

5

6

7

8

9

10

Hidetaka Nomaki ${ }^{\mathrm{a}}$, Charlotte LeKieffre ${ }^{\mathrm{b}}$, Stéphane Escrig ${ }^{\mathrm{b}}$, Anders Meibom ${ }^{\mathrm{b}, \mathrm{c}}$, Shinsuke Yagyu $^{\mathrm{d}}$, Elizabeth A. Richardson ${ }^{\mathrm{e}}$, Takuya Matsuzakid, Masafumi Murayama ${ }^{\mathrm{d}}$, Emmanuelle Geslin ${ }^{\mathrm{f}}$, Joan M. Bernhard ${ }^{\mathrm{g}}$

${ }^{a}$ Department of Biogeochemistry, Japan Agency for Marine-Earth Science and Technology, 2-15 Natsushima-cho, Yokosuka, Kanagawa, 237-0061, Japan

${ }^{\mathrm{b}}$ Laboratory for Biological Geochemistry, School of Architecture, Civil and Environmental Engineering (ENAC), Ecole Polytechnique Fédérale de Lausanne (EPFL), 1015 Lausanne, Switzerland

${ }^{\mathrm{c}}$ Center for Advanced Surface Analysis, Institute of Earth Sciences, University of Lausanne, Switzerland

d Center for Advanced Marine Core Research, Kochi University, B200, Monobe, Nankoku-city, Kochi, 783-8502, Japan

${ }^{\mathrm{e}}$ Georgia Electron Microscopy, University of Georgia, Athens, GA 30602, USA

${ }^{\mathrm{f}}$ LPG-BIAF, University of Angers, UMR CNRS 6112, 49095 Angers Cedex, France

${ }^{\mathrm{g}}$ Department of Geology and Geophysics, Woods Hole Oceanographic Institution, Woods Hole, MA 02543, USA

* Corresponding author: nomakih@jamstec.go.jp

Key words: Ultrastructure, NanoSIMS, micro-X-ray CT, correlative microscopy, isotope mapping, microhabitat 


\section{Abstract}

Transmission electron microscope (TEM) observation has revealed much about the basic cell biology of foraminifera. Yet, there remains much we do not know about foraminiferal cytology and physiology, especially for smaller benthic foraminifera, which inhabit a wide range of habitats. Recently, some TEM-coupled approaches have been developed to study correlative foraminiferal ecology and physiology in detail: Fluorescently Labeled Embedded Core (FLEC)-TEM for observing foraminiferal life-position together with their cytoplasmic ultrastructure, micro-X-ray computed tomography (CT)-TEM for observing and reconstructing foraminiferal cytoplasm in three dimensions (3D), and TEM-Nanometer-scale secondary ion mass spectrometry (NanoSIMS) for mapping of elemental and isotopic compositions at sub-micrometer resolutions with known ultrastructure. In this contribution, we review and illustrate these recent advances of TEM-coupled methods. 


\section{Introduction}

Benthic foraminifera are unicellular eukaryotes that are abundant constituents of the marine seafloor. Their habitats are diverse and, thus, as a group they encounter many different environmental conditions such as temperature, salinity, dissolved oxygen concentrations, water depths, trophic conditions, and redox conditions (reviewed in Murray 2006). It is expected that foraminifera have physiological adaptations to these various environments. Studies of their cytoplasmic structure are therefore keys to understanding how these microbial eukaryotes adapt to those different environmental conditions. Ultrastructural observation using a transmission electron microscope (TEM) has successfully been applied to foraminifera since the 1960s (Hedley et al. 1967; Dahlgren 1967a, b). The relationships between foraminiferal cellular ultrastructure and environments have been studied in a few cases (e.g., Leutenegger and Hansen 1979; Bernhard and Bowser 2008; Bernhard et al. 2006a, 2010a; 2010b). For instance, Virgulinella fragilis, which can thrive in micro-oxic and hydrogen sulfide-enriched environments, is known to support a double symbiosis with kleptoplasts and putative $\delta$-proteobacteria (Bernhard 2003; Tsuchiya et al. 2015). Although ultrastructural observations have cast light on many different aspects of foraminiferal metabolic diversity, TEM observation alone is not enough to determine the functions of all organelles. For example, incubation experiments are needed to establish the function of putative "symbionts" such as photosynthetic kleptoplasts (e.g., Jauffrais et al. 2016, 2017).

Also, recent advances on fine-scale analyses of porewater chemistry in sediments indicate both vertical and horizontal gradients and heterogeneity of constituents such as oxygen (Glud et al. 2005), nitrate (Glud et al. 2009; Metzger et al., 2016), dissolved reactive phosphorus, dissolved iron (Thibault de Chanvalon et al. 2015), and probably other compounds as well, at sub-millimeter length scales. Many benthic foraminifera are infaunal, particularly in mesotrophic to eutrophic sediments where they can utilize organic matter even in deep sediments (e.g., $>3 \mathrm{~cm}$ below the sediment-water interface; Jorissen et al. 1995). The micro-environments of infaunal foraminifera are, thus, highly diverse and heterogeneous, and can change temporally (Glud et al. 2005). Although foraminifera are able to migrate within sediments (Alve and Bernhard 1995; Moodley et al. 1998; Gross 2000; Heinz et al. 2001; Geslin et al., 2004; Nomaki et al. 2005; Koho et al. 2011), the ultrastructural characteristics observed with the TEM are likely to reflect the micro-environments that cannot be characterized with bulk-sediment analysis.

Recently, innovative methods using the TEM and coupled recent microanalytical technologies have been developed and applied to foraminiferal studies in efforts to overcome these challenges. The Fluorescently Labeled Embedded Core (FLEC) method is an excellent approach to reveal foraminiferal life position in sediments. The fluorescent tags are used to 
sediments with glutaraldehyde fixation and subsequent resin embedding. Because FLEC also labels additional organisms like ciliates and prokaryotes, it is also possible to observe interactions between foraminifera and these organisms together with foraminiferal ultrastructure observed with the TEM of the same sliced plane.

The complete sequential thin-section analysis of a whole organism or an array-tomography technique can be applied to study small-sized specimens (Yabuki et al. 2012, 2013; Micheva and Smith 2007). Because foraminifera are relatively large cells (hundreds of $\mu \mathrm{m}$ ), however, the complete ultrastructure of an entire foraminifera is difficult to reconstruct from TEM observations. One solution to the foraminiferal size issue is micro-X-ray computed tomography (CT), which also provides information on internal structures. Micro-X-ray CT has been used to assess attributes regarding foraminiferal tests (shells), such as biometry (Speijer et al. 2008; Briguglio et al. 2011, 2013; Hohenegger and Briguglio 2012; Ferrández Cañadell et al. 2014) and test-wall dissolution by means of X-ray attenuation (Johnstone et al. 2010; Iwasaki et al. 2015). Nomaki et al. (2015) applied X-ray CT to foraminiferal cells prepared for TEM (i.e., resin embedded; stained with heavy metals). Because micro-X-ray CT is nondestructive, observations of foraminiferal cytoplasmic structure with this technique prior to sectioning for TEM allow us to determine the precise positioning of sections that have particular cytoplasmic structures, such as extended reticulopodia, the cell periphery, chamber plugs, vacuoles, or multiple nuclei. The X-ray CT can also determine the surface area and volume of foraminiferal cytoplasm and selected structures, thus, permitting quantitative analyses of foraminiferal biovolume and growth pattern through chamber addition, as well as allowing an estimation of volumes and surface areas of vacuoles, which contain soluble compounds (Khalifa et al. 2016).

The combination of TEM and Nanometer-scale secondary ion mass spectrometry (NanoSIMS) can spatially investigate the elemental and isotopic compositions of organisms at sub-micrometer resolution (e.g., Finzi-Hart et al. 2009; Pernice et al. 2012; Carpenter et al. 2013; Hoppe et al., 2013; Kopp et al. 2015). In pulse-chase experiments with isotopically labeled substrates, it is therefore possible to quantitatively evaluate where within a cell, such as specific organelle types or endobionts, a certain molecule or its metabolic derivates were located at a given point in time (Nomaki et al. 2016; LeKieffre et al. 2017).

Here, we present three advanced TEM-coupled technologies applied to foraminiferal research; FLEC-TEM; micro-X-ray CT-TEM, and TEM-NanoSIMS. All these TEM-related methods provide valuable information on foraminiferal biology and ecology. Examples of these correlative technologies are presented along with summaries of each method, notes regarding advantages and disadvantages, and possible future applications.

\section{Materials and Procedures}




\subsection{FLEC-TEM}

Specimens were prepared using the FLEC-TEM method described by Bernhard and Richardson (2014). Foraminifera-bearing sediment cores were collected between July 23-25, 2007 from an area off Monterey, California (USA) with active hydrocarbon seepage, at approximately $36^{\circ} 44.7^{\prime} \mathrm{N} 122^{\circ} 16.6^{\prime} \mathrm{W}$ ( $\sim 1003 \mathrm{~m}$ water depth; Bernhard et al. 2010b), using pushcorers manipulated by the ROV Jason. The viability indicator CellTracker Green CMFDA (Thermo Fisher Scientific; Bernhard et al., 2006b) was injected into the pushcores and allowed to incubate in situ for approximately 1 day (Bernhard et al. 2009). For this study, two pushcores were utilized. One core, designated as the seep core, was collected adjacent to a clam bed (Bernhard et al., 2010b) while the other, designated the non-seep core, was collected $>25 \mathrm{~m}$ from visible active seepage. Aboard the surface vessel RV Atlantis, each core was subsampled with 1.5 -cm diameter syringe cores, which were preserved in $\sim 3 \%$ glutaraldehyde / 0.1 M cacodyllic acid ( $\mathrm{pH}$ 7.2). At WHOI (USA), syringe cores were further processed for FLEC as described in Bernhard and Bowser (1996) and Bernhard et al. (2003). Polymerized FLEC cores were sectioned perpendicular to the sediment-water interface using a Beuhler Low Speed Saw for rocks. Resulting sections were $\sim 0.5 \mathrm{~mm}$ in thickness. Fluorescent foraminifera were observed using an epifluorescence-equipped dissecting microscope (Leica FLIII with fluorescein / Green Fluorescent Protein filters; 490-nm bandpass excitation; 520-nm bandpass emission), which was used to note foraminiferal location in sediment slices along with their depth below the sediment-water interface. Select foraminifera were further imaged with an Olympus Fluoview Laser Scanning Confocal Microscope (LSCM) and then excised from their FLEC sediment slice using a sharp razor blade. Foraminifera were identified using morphology, test texture (mineralized vs. agglutinated), and knowledge of the local foraminiferal assemblage. In many cases, identification to species was not possible.

Blocks were trimmed as appropriate for TEM (Bernhard and Richardson, 2014), and sectioned with Diatome diamond knives into 1- $\mu \mathrm{m}$ thick sections for light microscopy and 70-nm thin sections for transmission electron microscopy. Thick sections were stained with toluidine blue and imaged with a Zeiss Axiovert 40C Tissue Culture microscope. Thin sections were post-stained with a solution of uranyl acetate (4\%) in ethanol and a modified version of Sato's lead citrate (Hanaichi et al., 1986). Transmission electron microscopy observations were made using a Zeiss 10CA TEM at the Marine Biological Laboratory (Woods Hole, MA, USA) or a JEOL JEM1011 TEM at the Georgia Electron Microscopy facility, University of Georgia (Athens, GA, USA).

2.2. Micro-X-ray CT

\subsubsection{Foraminiferal sampling and fixation}


The intertidal foraminifera Ammonia sp. (phylotype T6; Holzmann 2000, Hayward et al. 2004) was collected from the Nojima tidal flat $\left(35^{\circ} 19.4 \mathrm{~N} 139^{\circ} 38.1 \mathrm{E}\right.$; water depth, $\left.\sim 0 \mathrm{~m}\right)$ of Tokyo Bay on March 21, 2014. The deep-sea foraminiferal samples were collected from central Sagami Bay, Japan $\left(35^{\circ} 01.3 \mathrm{~N} 139^{\circ} 22.1 \mathrm{E}\right.$; water depth $\left.1430 \mathrm{~m}\right)$, during a cruise of $R / V$ Kaimei KM16-01 in April 2016. At the Nojima tidal flat, the top $\sim 1 \mathrm{~cm}$ of sediment was collected into several $4 \mathrm{~L}$ buckets for foraminiferal fixation in the laboratory. For Sagami Bay, sediment samples collected with a push corer were immediately sliced onboard into 0.5 - or $1-\mathrm{cm}$ sections to a depth of $6 \mathrm{~cm}$. The sediment samples were fixed in $10 \%$ glutaraldehyde in cacodylate buffer to a final concentration of $4.0 \%$ glutaraldehyde. In the laboratory, specimens that had an aggregation of sediment particles around their aperture and/or whose test was mostly filled with cytoplasm were isolated from the $>125-\mu \mathrm{m}$ size fraction using a binocular stereomicroscope.

\subsubsection{Post-fixation, staining and embedding into resin}

Sample post-fixation using osmium tetroxide, staining with uranyl acetate, and subsequent embedding into resin block followed the protocol for micro-X-ray and TEM sample preparation described previously (Nomaki et al. 2015). To yield high-contrast specimens for X-ray CT analysis, specimens were post-fixed and stained with osmium tetroxide and uranyl acetate. Osmium tetroxide is a conventional post-fixation agent that preserves lipids, and also some amino acids, peptides, and proteins to a lesser extent (Hayat 2000). Uranyl acetate stains nucleic acids and, to a lesser extent, proteins (Hayat 2000).

\subsubsection{Micro-X-ray CT imaging}

The resin-embedded Os- and U-stained foraminiferal specimens were imaged using a model Xradia 410 Versa microfocus X-ray CT system (Zeiss). An X-ray filter was attached to the X-ray source to reduce the X-ray energy to yield better resolution. The X-ray source setting was $40 \mathrm{kV}$ and $200 \mu \mathrm{A}$ for Bolivina spissa, and the exposure time for each projection was 10 seconds. A total of 1601 projections were performed during $360^{\circ}$ rotation and the resolution of the obtained image was $1.07 \mu \mathrm{m} /$ pixel. For Ammonia sp. (phylotype T6), different settings were applied: $60 \mathrm{kV}$ and $130-\mu \mathrm{A} \mathrm{X}$-ray source with 5 second projection for a total of 801 projections per $360^{\circ}$ rotation. The short projection time and lower numbers of projections for Ammonia sp. (phylotype T6) resulted in lower quality images compared to those of $B$. spissa. The obtained data were reconstructed using the manufacturer-supplied software and Osirix MD 6.5 (Pixmeo) software.

\subsection{TEM-NanoSIMS}

TEM-NanoSIMS analyses of benthic foraminifera was conducted independently in 
two different laboratories. Although the principal methods for our two sets of correlative TEM-NanoSIMS analyses were similar, there are several minor differences between Nomaki et al. (2016) and LeKieffre et al. (in press), as summarized in Tables 1 and 2. Below we describe similarities and differences in methodology.

\subsubsection{Incubation with stable-isotope tracer(s)}

Benthic foraminifera collected from Nojima tidal flat (Japan), Bourgneuf Bay (France), or Gullmar Fjord (Sweden) (Table 1, Nomaki et al. 2016, LeKieffre et al. in press and unpublished data) were incubated for different durations with different isotope tracers (as noted below). Ammonia sp. (phylotype T6) collected from the Nojima tidal flat were incubated with sediment either in dysoxic or anoxic conditions. Foraminifera were isolated from Bourgneuf Bay sediments (Ammonia sp. phylotype T6 and Haynesina germanica) and Gullmar Fjord sediments (Nonionellina labradorica) and incubated without sediments in artificial seawater (ASW, RedSea salt, salinity: 35). All foraminiferal specimens were incubated with additions of ${ }^{13} \mathrm{C},{ }^{15} \mathrm{~N}$, or ${ }^{34} \mathrm{~S}$ tracer(s) (Table 1, Nomaki et al. 2016; LeKieffre et al. in press and unpublished data).

\subsubsection{Fixation and embedding into resin}

After isotopic incubations, the Nojima flat sediments including benthic foraminifera were fixed in $10 \%$ glutaraldehyde in cacodylate buffer to a final concentration of $4.0 \%$ glutaraldehyde. Specimens whose tests (except for the ultimate one or two chambers) were filled with bright yellow cytoplasm typical of this Ammonia sp. (phylotype T6) were selected for analysis. Foraminifera from Bourgneuf Bay and Gullmar Fjord were, at the end of their incubation in isotope-spiked ASW, immediately fixed according to the chemical fixation protocol described in LeKieffre et al. (this issue). These glutaraldehyde-fixed foraminiferal specimens were either embedded in agarose (Nomaki et al. 2016) or directly decalcified (LeKieffre et al., in press), and then all specimens were post-fixed using osmium tetroxide. The Nojima specimens were additionally stained with uranyl-acetate "en-bloc" for $2 \mathrm{~h}$ followed by rinsing with distilled water. All samples were subsequently embedded in resin (Nomaki et al. 2016, LeKieffre et al. this issue, Koho et al. this issue).

\subsubsection{Sectioning, TEM imaging and coating}

Embedded specimens were sectioned into ultra-thin $(60-\mathrm{nm}$ to $70-\mathrm{nm}$ thick) or semi-thin (200-nm thick) sections. Sections were transferred to copper grids and stained with $2 \%$ aqueous uranyl acetate only (LeKieffre et al. in press) or $2 \%$ aqueous uranyl acetate followed by $0.3 \%$ lead nitrate and $0.3 \%$ lead acetate solution (Nomaki et al. 2016). In Nomaki et al. (2016), specimens' ultra-thin sections were used for detailed observations of organelle membranes to check cell integrity (e.g., intact mitochondrial cristae and 
230 double-membranes); semi-thin sections were used for subsequent TEM-NanoSIMS analyses. 231 In the case of LeKieffre et al. (in press) materials, the same ultra-thin sections were used for 232 both TEM and NanoSIMS. Once the target area for NanoSIMS analyses was selected, that 233 targeted region was observed sequentially and a composite of TEM images was reconstructed. 234 TEM-imaged sections intended for NanoSIMS analysis were coated with $20 \mathrm{~nm}$ of osmium 235 (Nomaki et al. 2016) or $10 \mathrm{~nm}$ of gold (LeKieffre et al. in press) to prevent samples from 236 electron charging during NanoSIMS analysis.

\subsubsection{NanoSIMS measurements}

Grids containing metal-coated sections were placed into the sample holder of a nanometer-scale secondary ion mass spectrometer (NanoSIMS NS50 or NanoSIMS 50L). The settings of the NanoSIMS analyses are summarized in Table 2.

During analysis, secondary ions were extracted with a primary $\mathrm{Cs}^{+}$beam. Different settings were used for the $\mathrm{Cs}^{+}$beam, resulting in a slightly different primary beam spot size on the two instruments) (Table 2). A multi-collector system was used to simultaneously measure five to seven different secondary ions (Nomaki et al. 2016; LeKieffre et al. in press). Areas of $8 \times 8-\mu \mathrm{m}$ to $30 \times 30-\mu \mathrm{m}$ were imaged with either $128 \times 128$ or $256 \times 256$ pixels rastered images. Sequential layers of images (up to 50) were accumulated to produce one image for each given area. The data quantification was performed after a drift correction of all layers, using the software ImageJ or L'IMAGE developed by Dr. Larry Nittler, Carnegie Institution of Washington, USA.

\subsubsection{Data analysis}

Correlation between NanoSIMS and TEM images was done by aligning the ${ }^{12} \mathrm{C}^{14} \mathrm{~N}^{-}$ ion image with the corresponding ultrastructural features in a TEM image. Values of ${ }^{15} \mathrm{~N}$ and ${ }^{34} \mathrm{~S}$ enrichments were obtained from the ${ }^{12} \mathrm{C}^{15} \mathrm{~N}^{-} /\left({ }^{12} \mathrm{C}^{14} \mathrm{~N}^{-}+{ }^{12} \mathrm{C}^{15} \mathrm{~N}^{-}\right)$or ${ }^{12} \mathrm{C}^{15} \mathrm{~N}^{-} /{ }^{12} \mathrm{C}^{14} \mathrm{~N}^{-}$and ${ }^{34} \mathrm{~S}^{-} /\left({ }^{32} \mathrm{~S}^{-}+{ }^{34} \mathrm{~S}^{-}\right)$or ${ }^{34} \mathrm{~S}^{-} /{ }^{32} \mathrm{~S}^{-}$ratios respectively, and presented as \%o enrichment over the natural isotope ratio measured in unlabeled samples prepared and analyzed identically. These ratios were calculated for selected regions of interest, using the program Look@NanoSIMS (Polerecky et al., 2012). This allows comparison of different cell compartments within the cytoplasm, or between different time points or incubation conditions (e.g., $\mathrm{pH}$, light, salinity, temperature, oxygen, presence/absence of a certain nutrient). It is noted that comparisons of isotopic ratios between samples from experiments using different sample preparation methods should be treated with caution as differences in sample preparation can lead to different isotopic ratios (Musat et al., 2014). For the data presented here, such effects did not significantly impact data interpretations.

\section{Results and Discussions}




\subsection{FLEC-TEM}

270

\subsubsection{Results}

Here, two foraminifera were designated for fluorescently labeled embedded core (FLEC)-TEM analyses, one individual from each ROV-collected core. In the non-seep core, the specimen was located at a sediment depth of $1.7 \mathrm{~cm}$ below the sediment-water interface. The upper edge of the core section shown in Fig. 1A was not the sediment-water interface. This specimen was tentatively identified as a Buliminella tenuata due to knowledge of the area's foraminiferal community (Bernhard et al., 2001; Bernhard et al., 2010b); it appeared to have intact cytoplasmic vacuoles in LSCM images (Fig. 1B). The test of this specimen was calcite, as evidenced by its appearance in reflected light (Fig. 1A) and in semi-thin section (Fig. 1C). The ultimate chamber of this individual contained little cytoplasm (Fig. 1B, C), which is to be expected given this is where reticulopods are deployed and retracted through the aperture (e.g., Alexander and Banner, 1984). This specimen also appeared to have a distinct layer of fluorescent material attached to the test (shell) exterior, as noted in the LSCM micrograph (Fig. 1B). In the sediments, the specimen was slightly inclined from horizontal, with the apertural end oriented deepest (Fig. 1B, C). What appears to be an open pore space is adjacent to the specimen's aperture (Fig. 1B, C).

In TEM micrographs of $B$. tenuata from the non-seep core, large vacuoles were visible (Fig. 2A). It is notable that osmication is not included in the FLEC-TEM preparation procedure. Thus, the membranes in FLEC-TEM specimens do not appear as distinctly as those membranes observed in specimens that were conventionally prepared for TEM (i.e., with osmication). What appeared to be degradation vacuoles (i.e., food vacuoles; see LeKieffre et al., this issue) were relatively common (Fig. 2A, B), containing items appearing to be prokaryotes as well as unidentifiable materials. Mitochondria were identified by their shape and size (Fig. 2B-D); in some cases cristae and the double membrane were discernable (Fig. 2C), but not clearly. The mitochondria appeared to occur at the cell periphery, as well as far from the periphery, well within the cell. Electron-opaque bodies, sensu LeKieffre et al. (this issue) (also known as "electron dense bodies"; Nomaki et al., 2016), were also observed (Fig. 2C-E). Golgi were also noted (Fig. 2 B-D), as were peroxisomes with endoplasmic reticulum (Fig. 2E). The crystalized core (catalase) of peroxisomes (Fig. 2E inset; Bernhard and Bowser, 2008) was not as distinctive in these preparations compared to those subject to conventional TEM processing with osmication. There was no evidence of prokaryotic endobionts (i.e., endosymbionts) in this foraminiferan. Examination of the area immediately adjacent to what would have been the test exterior revealed that the fluorescent material observed in the LSCM image (Fig. 1B) was not prokaryotic (i.e., ectobionts) but was most likely foraminiferal reticulopods (Fig. 2F, G). Because we did not fix the FLEC cores to preserve reticulopods (Travis and Bowser 1986, Bernhard et al., 2013), well-preserved 
reticulopodial networks were not expected, but such structures (Fig. 2F, G) are not inconsistent with reticulopodial cytoplasm.

The foraminifer from the seep core was agglutinated, evidenced by the brownish color of the test (Fig. 3A), especially when compared to a calcareous (white) foraminifer in the same image. This agglutinated seep specimen was clearly biserial but we were not confident in identifying this specimen to a genus or species. The specimen aperture was located at a sediment depth of $1.7 \mathrm{~mm}$ below the sediment-water interface (Fig. 3A, B), near a juvenile clam. Microbes (eukaryotes and/or prokaryotes) also occurred in these sediments (Fig. 3B), but no additional foraminifera visible in reflected light (Fig. 3A) were living (i.e., fluorescent; Fig. 3B). The biserial seep specimen was oriented with its aperture facing downward, at a $\sim 45^{\circ}$ angle from horizontal (Fig. 3A, B). As in the B. tenuata, the ultimate (youngest) chamber of this agglutinated individual was less fluorescent, indicating presence of less cytoplasm than in middle chambers (Fig. 3B, C). Mineral grains in the test of the specimen can be discerned in some places (Fig. 3C).

The LSCM image of the biserial agglutinant shows it had visible cytoplasmic vacuoles, as well as one large nucleus (Fig. 3C). Compared to the exterior surface of the non-seep specimen's test, this seep specimen lacked an obvious layer of fluorescent material on its test exterior. However, it is clear that short filamentous prokaryotes occurred in sediments in the vicinity of this seep specimen (Fig. 3C). What appears to be either a feeding bolus or reticulopodial trunk is located in the apertural region (Fig. 3C). Because of this specimen's large size, only the older portion of its test was excised and subject to ultrastructural analysis.

The TEM micrographs of the agglutinated seep specimen show the presence of large cytoplasmic vacuoles (Fig. 4), most of which lacked preserved membranes. Degradation vacuoles were present (Fig. 4A, B) but not as common as in the non-seep B. tenuata specimen. In the space between the organic lining and the interior surface of the test, prokaryotes were sometimes observed (Fig. 4B). There was no evidence of endosymbionts in the endoplasm, although some vacuoles appeared to contain one or two items that appeared to be prokaryotes (Fig. 4A); the identity and role of these microbes is not certain but the reader is directed to the contribution in this issue on prokaryotic associates (e.g., symbionts, parasites; Bernhard et al., this issue). Smaller vacuoles (Fig. 4C, D) appeared to have preserved membranes. Given the slight contrast due to lack of osmication (see above), mitochondria were identified on the basis of size and shape (Fig. 4C, D). In some mitochondria (Fig. 4C, D), a double membrane was clearly noted. The mitochondria did not appear to occur exclusively at the cell periphery. Peroxisomes were noted occasionally in characteristic distributions with endoplasmic reticulum at vacuole peripheries (Fig. 4D; Bernhard and Bowser, 2008); Golgi was also noted (not shown). 


\subsubsection{FLEC-TEM Methodological notes}

Correlative epifluorescence and TEM methods are not novel (e.g., Rieder and Bowser, 1987). The FLEC-TEM approach, which was recently described (Bernhard and Richardson, 2014), is novel in that it allows examination of cellular attributes in specimens that are located within sediments, where they lived at the time of fixation. The ability to observe the life position of foraminifera, or any other meiofauna, is advantageous to ecological studies but the method does have disadvantages, some of which are discussed in Bernhard and Richardson (2014). Briefly, the disadvantages of FLEC-TEM are: (1) Sectioning of specimens among sediments will expose the diamond knife to heavy use, likely causing damage and the need for resharpening. A novel method that merges use of a focused ion beam (FIB) with the use of a scanning electron microscope (SEM) can produce TEM-quality ultrastructural information in cells (Narayan and Subramaniam, 2015), although this FIB-SEM method has not been performed on foraminifera, to our knowledge. (2) Also, as noted, the lack of osmication prevents preservation and detection of some membranes. Apparent lack of membranes in FLEC-TEM specimens does not necessarily mean the membranes did not exist at the time of fixation. (3) Another disadvantage involves fixation rate. Typically, when materials are preserved in glutaraldehyde, the fixation process is quick because specimens are immersed directly into the fixative solution. With FLEC fixation, however, the fixative must percolate into the sediments contained in the syringe core. Depending on the pore-water content and sediment porosity, as well as specimen location (e.g., deep infaunal vs. epifaunal), fixation of FLEC samples may be considerably slower than immediate fixation of isolated individuals. The slower speed of fixation could impact cellular preservation in unknown ways. (4) Foraminiferal identification at the species or genus level hinges on the plane of section; confident identification can be difficult to impossible. Depending on the study objective(s), such constraints may not be an issue. (5) For some studies, it is imperative to distinguish living from dead specimens (e.g., Bernhard et al., 2010b). Our experience with FLEC-TEM to date indicates that viability in specimens prepared with this method is inconclusive because, for example, mitochondrial status (cristae and double membrane) is not clearly discernable. While significantly degraded cytoplasm is easily detected, any conclusions asserting that a specimen analyzed with FLEC-TEM was living at the time of preservation should be made with due caution.

\subsubsection{Methodological advantages: Merging ecology and physiology}

Advantages of the FLEC-TEM method include the ability to pair fine-scale distribution with cellular attributes, as described in Bernhard and Richardson (2014) and discussed further below. Because foraminifera move relatively slowly, we expect that the position of individual foraminifera observed in FLEC sections is where the individual lived, unless it was entrained down the core barrel at the edge of the core. Thus, we can distinguish 
between surface-living (epifaunal) and deep-dwelling (infaunal) specimens, and we can observe the fitness of each of those cells. In addition to determining position in sediments and orientation of the aperture, FLEC also allows observation about the microhabitat of the individual foraminifer. Thus, the sediment texture, fabric, and pore space can be assessed, as can attributes regarding the neighboring microbial community. If neighbors have distinct morphologies, we can determine if particular types of organisms consistently associate together (Bernhard et al. 2003).

On the cellular scale, FLEC-TEM allows insights regarding adaptations and diet, which can be particularly insightful when considering the fine-scale location of any given individual within sediments, especially in chemoclines where steep geochemical gradients exist. Furthermore, FLEC-TEM can determine if individuals collected from oxygen-depleted environments have specialized features, such as prokaryotic associates, putative symbionts, numerous peroxisomes, or peripheral / pore-plug associated mitochondria.

3.1.4 Observations on the paired ecology and physiology of these seep and non-seep foraminifers

Due to the discernable double membrane and cristae noted in some mitochondria, relatively intact peroxisomes, endoplasmic reticulum and Golgi, as well as abundant degradation vacuoles, and presence of reticulopodial remains on the test exterior (Fig. 2), we assert that the non-seep Buliminella tenuata specimen was active (i.e., living) at the time of fixation. Because this specimen was located at a sediment depth of $1.7 \mathrm{~cm}$, the pore-waters bathing this specimen at the time of collection likely were depleted in oxygen (e.g., Bernhard, 1992). There was no evidence of the foraminifer being directly associated with any burrows or tubes, although one tube was present in FLEC sections from the other side of the $1.5-\mathrm{cm}$ diameter FLEC core. Burrows and tubes can oxidize pore waters at depth (e.g., Thibault de Chanvalon et al., 2015). We note that this non-seep B. tenuata had mitochondria both at the cell periphery as well as further inside the cell. Foraminifera from low-oxygen habitats often concentrate mitochondria at the cell periphery (e.g., Bernhard et al., 2010a; Leutenegger and Hansen, 1979; see also LeKieffre et al., this issue) but can also have mitochondria throughout the cell. Additional evidence that the specimen was living in oxygen-depleted pore waters is the presence of characteristic peroxisome-endoplasmic reticulum complexes that are often noted in specimens from low-oxygen habitats (Bernhard and Bowser, 2008; see also LeKieffre et al., this issue). The specimen lacked evidence of endosymbionts, which is consistent with the non-seep habitat.

The results presented here on the agglutinated seep foraminifer are valuable because, to our knowledge, observations of the cell ultrastructure and organelle attributes of multi-chambered deep-sea agglutinated foraminifera are not published. This lack of published micrographs likely is because such robust agglutinated tests are extremely challenging to 
section.

As with the non-seep B. tenuata, assessing viability in the seep-associated biserial agglutinated foraminiferan is difficult. Mitochondria with double membranes and partially discernable cristae were present, as were additional organelles (e.g., peroxisomes, endoplasmic reticulum, small vacuoles with membranes, Golgi), suggesting the specimen was living or recently living. The association of the peroxisomes with the periphery of large vacuoles adds support that this agglutinated foraminifer was living in the seep habitat because, as noted, many foraminifera living in steep chemoclines have such associations (Bernhard and Bowser, 2008; Bernhard et al., 2010b; Martin et al., 2010). The presence of a bolus or reticulopodial trunk in the apertural region (Fig. 3C) provides additional evidence that the agglutinated specimen was active at the time of fixation. The relative dearth of degradation vacuoles suggests the specimen may not have been particularly active at the time of fixation, although it appears that the foraminifer was ingesting prokaryotes (Fig. 4A). It is possible that more degradation vacuoles appeared in the younger part of the specimen that was not examined with TEM.

The seep-associated agglutinated foraminiferan did not appear to be migrating toward the sediment-water interface because its aperture was oriented downward (Fig. 3). Generally, foraminifera move in the direction that their aperture points (e.g., Heinz 1999; H. Nomaki, pers. obs.). Thus, if we assume the specimen was living at the time of fixation, it was not adverse to the localized seep chemistry. Unfortunately, we lack porewater chemical analyses on this specific FLEC core, but the pushcore was collected adjacent to an active chemosynthetic mussel bed. Also, we note presence of some filamentous prokaryotes (Fig. $3 \mathrm{C}$ ) in the vicinity of the foraminiferan; these filaments could be the sulfide oxidizing Beggiatoa, which is commonly known to occur in seeps (e.g., Lloyd et al. 2010).

\subsection{Micro-X-ray CT-TEM}

\subsubsection{Results}

The X-ray computed tomography (CT) imaging using the Os- and U-stained foraminifera embedded in resin block showed three-dimensional (3D) structures of foraminiferal cytoplasm (Figs. 5 and 6, Supplementary movies 1, 2, and 3). Using different contrast settings in the software, we were able to observe both external morphology (e.g., Supplementary movie 2) and internal structures larger than several micrometers (e.g., Supplementary movie 3). In a specimen of Ammonia sp. (phylotype T6), we observed that the cytoplasm of the ultimate 3 to 5 chambers were less dense in comparison to that of the other chambers based on the differences in X-ray attenuation (Fig. 5A, C, Supplementary movie 1), probably reflecting more vacuoles (Nomaki et al. 2014) and less lipid droplets (Koho et al. this issue), together with less staining of the cytosol (data not shown). Many chambers in the last whorl had relatively large vacuoles $(\sim 50 \mu \mathrm{m}$ in diameter) close to the axis of rotation (Fig. 
5C). A chamber marked with a white arrowhead in Fig. 5A showed a cytoplasmic depression; this void between the calcite test and cytoplasm is sometimes observed for certain specimens and might be an artifact due to the shrinkage of the cytoplasm during the fixation process. In a specimen of Bolivina spissa, the last 2 chambers were "frothy" and not all the chamber space was occupied with cytoplasm (Fig. 6A, B, Supplementary movie 2). The proloculus cytoplasm also looked less dense than other chambers' cytoplasm (Fig. 6C). Cross sectional views showed many vacuoles of 10 - to $30-\mu$ m diameter throughout all chambers (Fig. 6D, E). Another obvious structure that was observed with micro-X-ray CT is plugs, which had high electron density due to uranium staining (Fig. 6D, Supplementary movie 3; Nomaki et al. 2015). Plugs are hypothesized to provide a means to partition portions of the cell not only among different chambers but also into different volumes, which, hypothetically, perform different intracellular biochemical reactions (Hottinger 2000; Ferrández Cañadell 2002). Sometimes, plugs were observed in each chamber of an entire foraminiferal specimen (Nomaki et al. 2015). In some specimens, sediment particles around the aperture and trunks of reticulopods extending from the aperture were also observed (not shown).

\subsubsection{Advantages and applications}

The advantage of the micro-X-ray CT is to provide an overall view of cytoplasmic conditions, allowing one to target characteristic areas or organelles (e.g., vacuoles, plugs, nucleus). These observations greatly help us to determine the positions of TEM sections. Also, the whole-specimen perspective helps to evaluate the representativeness of the observed ultra-thin section(s) in the observed specimen. Pre-observation of the resin-embedded specimens using micro-X-ray CT before sectioning for TEM observation may become common when micro-X-day CT scanning becomes more affordable and faster.

Another advantage of micro-X-ray CT is the ability to quantify the volume or surface area of the region of interest (Nomaki et al. 2015). The volume of cytoplasm in each chamber allows, e.g., calculation of the biovolume, growth pattern through chamber addition, and assessment of fitness. The total cell volume and volume of each vacuole also provides information to estimate the total chemical contents or concentrations in vacuoles. The cytoplasm-occupancy ratio seems to differ greatly between chambers and between species (Figs. 5 and 6, Nomaki et al. 2015), reflecting the volume of vacuoles that might be affected by their environment (LeKieffre et al., this issue).

\subsubsection{Spatial resolution limitations}

The spatial resolution of the micro-X-ray CT continues to improve; the current spatial resolution of the commercial micro-X-ray CT, e.g. Xradia 410 Versa (ZEISS, this study) or SkyScan 1272 (Bruker; Nomaki et al. 2015), is as low as $0.35 \mu \mathrm{m}$. Furthermore, because the differences in X-ray attenuation between metal-labeled cytoplasm and resin are not large as 
496

between calcite (test) and air (e.g., Iwasaki et al. 2015), identification of small organelles like mitochondria and peroxisomes remains difficult. Certain studies using full-field or scanning X-ray microscopes and scanning transmission X-ray microscopes reported 50- or 60-nm resolution of internal fungal features (Larabell and Le Gros 2004; Le Gros et al. 2005), indicating there is potential to observe small organelles in foraminifera. Such high-resolution images, however, can be achieved only for some limited target areas, not for whole foraminiferal cells. High-resolution 3D observations of limited areas are also achieved using a focused ion beam scanning electron microscope (FIB-SEM; e.g., Lucas et al. 2014) technology at a voxel size of 5 to $10 \mathrm{~nm}$ with a maximal sample size of $50 \times 30 \times 30 \mu \mathrm{m}$ in volume, which remains a small fraction of foraminiferal cell size.

\subsection{TEM-NanoSIMS}

\subsubsection{Elemental and isotope mapping and quantification}

Nanometer-scale secondary ion mass spectrometry (NanoSIMS) analyses on a target area of ultra-thin sections or semi-thin sections (Fig. 7A) previously observed with a TEM (Fig. 7B, C) provide qualitative elemental concentration data and stable isotope ratios for imaged and identifiable ultrastructural features (Fig. 7D, E). NanoSIMS ${ }^{12} \mathrm{C}^{14} \mathrm{~N}^{-}$ion images contain a wealth of ultrastructural information that enables precise correlation with TEM images (Fig. 7D, E).

An example of isotopic ratio analysis using Look@NanoSIMS showed quantitative information on isotopic compositions of each region of interest (ROI) (Fig. 8). In this example, the foraminifer was fed with ${ }^{13} \mathrm{C}$-enriched diatoms (d), which were observed with their silica frustules in the foraminiferal endoplasm (Fig. 8A). The ROIs based on the TEM image can be correlated with obtained NanoSIMS images (Fig. 8B, C, D), including isotopic ratios (Fig. 8E), and the quantitative data can be summarized into a table (Fig. 8F).

\subsubsection{Examples of 5 different isotope labels}

Elemental ratios provide qualitative indications of relative $\mathrm{C}$ and $\mathrm{N}$ contents in measured areas corresponding to different organelles or ultrastructural features. For example, regions of lipid droplets exhibited lower $\mathrm{N}$ concentrations relative to other organelles and the cytosol (Fig. 7D, E). This may reflect low concentrations of $\mathrm{N}$ in lipid droplets (and also in the embedding resin), which have been thought to store lipids as a carbon source (LeKieffre et al. 2017, submitted), although the actual contents of "lipid droplets" are not well understood. On the other hand, certain organelles like mitochondria exhibited higher $\mathrm{N}$ concentrations than those of the cytosol (Fig. 7D, E; see clearer image in Fig. 2 of Nomaki et al. 2016).

The stable isotopic compositions of $\mathrm{C}, \mathrm{N}$, and $\mathrm{S}$, which are calculated with the ratios 
of ${ }^{13} \mathrm{C}^{12} \mathrm{C}^{-/ 12} \mathrm{C}_{2}^{-},{ }^{12} \mathrm{C}^{15} \mathrm{~N}^{-} /\left({ }^{12} \mathrm{C}^{14} \mathrm{~N}^{-}+{ }^{12} \mathrm{C}^{15} \mathrm{~N}^{-}\right)$or ${ }^{12} \mathrm{C}^{15} \mathrm{~N}^{-} /{ }^{12} \mathrm{C}^{14} \mathrm{~N}^{-}$, and ${ }^{34} \mathrm{~S}^{-} /\left({ }^{32} \mathrm{~S}^{-}+{ }^{34} \mathrm{~S}^{-}\right)$or ${ }^{34} \mathrm{~S}^{-} /{ }^{32} \mathrm{~S}^{-}$, respectively, show the localization of the added stable isotope labels (Fig. 9). For example, the addition of ${ }^{13} \mathrm{C}$-labeled diatoms revealed the incorporation of food materials (Fig. 9A). While most ${ }^{13} \mathrm{C}$-labeling was observed within the organic material contained in the diatom frustules, one spot outside a diatom frustule exhibited high ${ }^{13} \mathrm{C}$-concentrations (lower left of Fig. 9A), suggesting the $\mathrm{C}$ in this region was derived from a digested diatom.

The addition of ${ }^{13} \mathrm{C}$-enriched inorganic $\mathrm{C}\left(\mathrm{H}^{13} \mathrm{CO}_{3}{ }^{-}\right)$provides information on autotrophic/anaplerotic $\mathrm{C}$ fixation into biomass (Fig. 9B). In the example provided in Fig. 9B, foraminifera were supplied with $\mathrm{H}^{13} \mathrm{CO}_{3}^{-}$to investigate the autotrophic metabolism of kleptoplastic benthic foraminifera. Because soluble ${ }^{13} \mathrm{C}$-compounds are generally lost from the cell during TEM sample preparation (see section 3.2.4.), the isotope enrichments measured with the NanoSIMS represent 'structural' organic molecules derived from $\mathrm{H}^{13} \mathrm{CO}_{3}$ '. This data showed the ${ }^{13} \mathrm{C}$-assimilated by photosynthetic symbiont and its subsequent transfer and re-processing within the foraminiferal cell.

The assimilation of inorganic sources of ${ }^{15} \mathrm{~N}$ (e.g., ammonium or nitrate) can provide an important assessment of nitrogen assimilation and translocation within foraminiferal cells (Fig. 9C, D). Both ammonium and nitrate are important $\mathrm{N}$ sources for amino acid synthesis in autotrophic organisms, including foraminiferal symbionts or organelles like kleptoplasts. Here, assimilation of ${ }^{15} \mathrm{~N}$ originating from ${ }^{15} \mathrm{NH}_{4}{ }^{+}$was observed as small spots of less than 1 $\mu \mathrm{m}$ in diameter, corresponding to electron-opaque bodies (Fig. 9C). Similar assimilation of ${ }^{15} \mathrm{~N}$ into electron opaque bodies (called "electron dense bodies" in Nomaki et al. 2016) was also observed in the specimens incubated with ${ }^{15} \mathrm{NO}_{3}{ }^{-}$(Fig. 9D). Nitrogen isotopic compositions of amino acids in Ammonia sp. (phylotype T6) incubated with ${ }^{15} \mathrm{NO}_{3}{ }^{-}$indicated that those ${ }^{15} \mathrm{~N}$ labels existed as amino acids probably originated from endobiotic prokaryote (Nomaki et al. 2014; reported as Ammonia beccarii). Enrichments in ${ }^{15} \mathrm{~N}$ were obvious in electron-opaque bodies of the Ammonia sp. (phylotype T6) incubated in anoxia (Fig. 9D), but were also obvious in mitochondria, cytoplasm, and food vacuoles in dysoxia-incubated specimens, suggesting metabolism varied under different oxygen concentrations (Nomaki et al. 2016). Organic lining and lipid droplet regions were modestly labeled with ${ }^{15} \mathrm{~N}$ even after 14 days, indicating slower turnover than for other organic matter.

Using ${ }^{34} \mathrm{SO}_{4}{ }^{2-}$ as an isotope tracer in Ammonia sp. (phylotype T6) allowed visualization of ${ }^{34} \mathrm{~S}$ localization in the cytoplasm (Fig. 9E), likely resulting from metabolism related to sulfur assimilation and/or sulfate reduction by symbionts. Enrichments in ${ }^{34} \mathrm{~S}$ were detected in various opaque bodies, but enrichment was also detected in the cytoplasm near vacuoles or as remains inside vacuoles (Fig. 9E). As observed for ${ }^{15} \mathrm{~N},{ }^{34} \mathrm{~S}$ assimilation was more pronounced in the specimens incubated with dysoxia versus those incubated in anoxia. 


\subsubsection{Methodological advantages and applications}

The main advantage of correlated TEM-NanoSIMS observations is the small scale imaging of elements and isotopes. Indeed, this method allows the sub-cellular localization of isotopically labeled compounds, and gives the possibility to quantify isotopic ratios at the scale of organelles (micron to sub-micron scales). Such knowledge has wide applications to studies of foraminiferal biology and physiological processes such as symbiosis, kleptoplasty, trophic metabolism or denitrification. The use of labeled key elements combined with an appropriate incubation time(s) (see below) can also be used to study foraminiferal metabolism under different laboratory-controlled conditions, such as oxic vs. dysoxic conditions or light/dark incubations. For instance, symbiosis between ecto-/endobionts or algal symbionts and foraminifera, widely reported in the literature (e.g., Lee and Hallock 1987; Lee and Anderson 1991; Bernhard et al. 2000, 2006a, 2010a), are obvious candidates for correlated TEM-NanoSIMS study, because little is known yet about the role of the symbionts or the metabolite transfer between the symbionts and the host cell. For example, phylogenetic studies of Virgulinella fragilis endobionts suggest they are putative sulfate reducing $\delta$-proteobacteria (Tsuchiya et al. 2015). The close phylogenetic relationship between the $V$. fragilis endobionts and sulfate reducing $\delta$-proteobacteria suggests these endobionts use organic matter from the host for carbon oxidation. In another example, a study using a radio-isotope tracer in foraminifera containing different algal symbionts suggested that metabolites exchanged between host foraminifera and algal symbionts differed between diatom-retaining foraminifera and dinoflagellate-retaining foraminifera (Kremer et al. 1980). However the Kremer et al. study performed a bulk cell analysis of radio-isotope label transfer, without any spatial information inside the foraminifera. The use of TEM-NanoSIMS with stable isotope labeling could identify the transfer of target elements from specific symbionts to foraminifera or vice versa at a sub-micron scale.

Time-series sampling in incubation experiments is important for elucidating the actual pathways of the label into foraminiferal ultrastructure or symbiotic partners. For instance, the use of ${ }^{13} \mathrm{C}$-labeled diatoms as a foraminiferal food source (Figs. 8 and 9A) in a longer incubation reveals the ${ }^{13} \mathrm{C}$-assimilation into the foraminiferal biomass. The extent of labeling differs between ultrastructural features (i.e., heterogeneity), showing localization in specialized features such as lipid droplets (LeKieffre et al., 2017). Further, prolonged incubations should result in the ${ }^{13} \mathrm{C}$-label being respired into ${ }^{13} \mathrm{CO}_{2}$ and the ${ }^{13} \mathrm{C}$-signal in the cytoplasm decreasing over time. The use of NanoSIMS to trace ${ }^{13} \mathrm{C}$ - or ${ }^{15} \mathrm{~N}$-labeled organic matter with appropriate time series sampling, thus has great advantages in metabolic and stoichiometric studies of foraminifera, because one could estimate not only food selectivity but also turnover rates of each organelle type.

\subsubsection{Limitations and challenges}


NanoSIMS analysis cannot discriminate which organic molecules were isotopically labeled. Thus, NanoSIMS imaging cannot determine the exact nature of the compounds transferred, but isotope-label localization with ultrastructural observations can provide some guidance. Nevertheless, employing a suite of multiple approaches, such as compound specific isotope analysis of metabolites, genomic and transcriptome analyses, organelle purification with their chemical analyses, in combination with TEM-NanoSIMS, will provide a clearer comprehension of foraminiferal cell metabolism.

Isotopically labeled compounds originally introduced into experiment treatments are not necessarily stable. As incubations proceed over time, labeled substrates can be transformed into other compounds and be available to all entrained organisms in the experimental conditions. Thus the observed isotope-enriched parts in the foraminifera do not necessarily indicate the assimilation of the original labeled compounds, but could indicate the assimilation of other compounds metabolically derived from the original substrates. For example, ammonium or nitrate can be quickly metabolized into ammonium/nitrite/nitrate via microbial processes in the seawater or in sediments (Francis et al. 2007; Libes 2009). Thus the isotope enrichments observed in a long-term experiment requires careful interpretations. Short-term experiments, on the other hand, may be insufficient to label materials for TEM-NanoSIMS analyses that have lower sensitivity than conventional bulk isotope analyses such as EA/IRMS.

Another limitation of the current TEM-NanoSIMS method is that the content of vacuoles and associated soluble compounds in the cytosol (e.g., free amino acids, inorganic carbon, or ions like nitrate and ammonium) are lost during sample preparation. This is unfortunate because these compounds are very important for assessing foraminiferal denitrification, calcification, assimilation and dissimilation processes. Cryofixation of foraminiferal cells (Goldstein and Richardson 2002, this issue) is a potential way to examine those soluble components in the foraminiferal cytosol. Cryofixation is a fixation protocol that preserves a sample with high-pressure freezing at extremely low temperature (Moor 1987). Recently, elemental mapping of the foraminiferal cytoplasm, vesicles and vacuoles using cryofixation reported presence of vacuoles containing calcium in seawater in a cryo-fixed Amphistegina lobifera (Khalifa et al, 2016). This is a good example that cryofixation maintains soluble compounds in vacuoles that may be lost during conventional sample preparation protocols. NanoSIMS analyses of cryopreserved specimens should provide more complete information on elemental and isotopic localizations in foraminiferal cells.

From a logistical and resource perspective, TEM-NanoSIMS is a time-consuming method due to sample preparation steps, TEM observation, and isotope mapping using NanoSIMS. Additionally, the instrumentation is costly and can be difficult to access. These facts result in generally low numbers of analyzed TEM-NanoSIMS specimens per experimental condition, hampering generalization of results. 


\section{Conclusion}

The three TEM-related techniques provide a novel perspectives into foraminiferal ecology and biology on different spatial and temporal scales. FLEC-TEM provides sub-millimeter-scale information on foraminiferal life positions and microhabitats in terms of living depth and surrounding milieu including sediment fabric, porosity and meio- and microfaunal communities, all related to foraminiferal ultrastructure and fitness. Micro-X-ray CT-TEM provides 3D views of foraminiferal cells to assess cytoplasmic features such as vacuolization extent to provide volumetric and areal information useful to biomass/biovolume assessments. TEM-NanoSIMS provides micron to nanometer scale information on the distributions of elemental and isotopic compositions in foraminifera along with ultrastructural information, yielding important information about foraminiferal metabolism at the organelle to endobiont scale. Although each of these techniques has limitations, the advantage of correlation with TEM imaging provides different ways to link cell ultrastructures with metabolic processes, ultimately better defining foraminiferal roles in biogeochemical cycling and microbiome ecosystem functioning.

\section{Acknowledgments}

We thank Ms Kaya Oda (JAMSTEC) for the preparation of the Japanese TEM samples; Katsuyuki Uematsu and Akihiro Tame (Marine Works, Japan) for TEM observations; Akizumi Ishida, Yuji Sano, Naoto Takahata (The University of Tokyo) for NanoSIMS analyses; Chon Chen (JAMSTEC) for help with the onboard sampling of the sediment samples from the bathyal Sagami Bay during the KM16-01 cruise. The electron microscopy platform at the University of Lausanne (Switzerland) is thanked for access and technical assistance. JMB thanks her collaborators Tony Rathburn and Jon Martin on the original seep foraminifera project, Sam Bowser and Sue Goldstein for insightful conversations, Kasia Hammar and Louie Kerr for TEM assistance at the Marine Biological Laboratory (Woods Hole, MA, USA), and the Georgia Electron Microcopy facility at UGA. The comments raised from Prof. Howard Spero and an anonymous reviewer greatly improved our manuscript. This contribution was edited by Prof. Richard Jordan. This work was financially supported by the Grant-in-Aid for Scientific Research from the Ministry of

680 Education, Culture, Sports, Science and Technology, Japan (Scientific Research (C) grant 681 number $17 \mathrm{~K} 05697$ to $\mathrm{HN}$ ) and the Swiss National Science Foundation (grant no. 200021_149333). JMB's contributions were funded by US NSF grants OCE-0551001 and OCE-1634469, the WHOI Robert W. Morse Chair for Excellence in Oceanography, and The Investment in Science Fund at WHOI. The micro-X-ray CT imaging was performed under the 
686

687

688

689

690

691

692

693

694

695

696

697

698

699

700

701

702

703

704

705

706

707

708

709

710

711

712

713

714

715

716

717

718

719

720

721

722

University (accept No. 17A021).

\section{References}

Alexander, S.P., Banner, F.T., 1984. The functional relationship between skeleton and cytoplasm in Haynesina germanica (Ehrenberg). J. Foramin. Res. 14, 159-170.

Alve, E., Bernhard, J. M., 1995. Vertical migratory response of benthic foraminifera to controlled oxygen concentrations in an experimental mesocosm. Mar. Ecol. Prog. Ser. $116,137-151$.

Bernhard, J.M., 1992. Benthic foraminiferal distribution and biomass related to pore-water oxygen content- Central California Continental Slope and Rise. Deep-Sea Res. 39 (3-4A), 585-605.

Bernhard, J. M., 2003. Potential symbionts in bathyal foraminifera. Science 299, 861. doi: 10.1126/science. 1077314

Bernhard, J.M., Bowser, S.S., 1996. Novel epifluorescence microscopy method to determine life position of foraminifera in sediments. J. Micropalaeontol. 15, 68.

Bernhard, J. M., Bowser. S. S., 2008. Peroxisome proliferation in foraminifera inhabiting the chemocline: an adaptation to reactive oxygen species exposure? J. Eukaryot. Microbiol. 55, 135-144 doi: 10.1111/j.1550-7408.2008.00318.x

Bernhard, J. M., Richardson, E. A., 2014. FLEC-TEM: Using microscopy to correlate ultrastructure with life position of infaunal foraminifera. In Approaches to Study Living Foraminifera: Collection, Maintenance and Experimentation. [Kitazato, $\mathrm{H}$. Bernhard, J. M. eds] Springer Japan

Bernhard, J. M., Buck, K. R., Farmer, M. A., Bowser, S. S., 2000. The Santa Barbara Basin is a symbiosis oasis. Nature 403, 77-80, doi:10.1038/47476

Bernhard, J. M., Buck, K. R., Barry, J. P., 2001. Monterey Bay cold-seep biota: Assemblages, abundance, and ultrastructure of living foraminifera. Deep-Sea Res. PT I 48 (10), 2233-2249. doi: 10.1016/S0967-0637(01)00017-6

Bernhard, J. M., Visscher, P. T., Bowser, S. S., 2003. Submillimeter life positions of bacteria, protists, and metazoans in laminated sediments of the Santa Barbara Basin. Limnol. Oceanogr. 48 (2), 813-828. doi: 10.4319/lo.2003.48.2.0813

Bernhard, J. M., Habura, A., Bowser, S. S., 2006a. An endobiont-bearing allogromiid from the Santa Barbara Basin: Implications for the early diversification of foraminifera. J. Geophys. Res. 111, G03002, doi:10.1029/2005JG000158

Bernhard, J. M., Ostermann, D. R., Williams, D. S., Blanks, J. K., 2006b. Comparison of two methods to identify live benthic foraminifera: A test between Rose Bengal and CellTracker Green with implications for stable isotope paleoreconstructions. Paleoceanography 21, PA4210, doi:10.1029/2006PA001290 
Bernhard, J. M., Barry, J. P., Buck, K. R., Starczak, V. R., 2009. Impact of intentionally injected carbon dioxide hydrate on deep-sea benthic foraminiferal survival. Glob. Change Biol. 15:2078-2088. doi: 10.1111/j.1365-2486.2008.01822.x

Bernhard, J. M., Goldstein, S. T., Bowser, S. S., 2010a. An ectobiont-bearing foraminiferan, Bolivina pacifica, that inhabits microxic pore waters: cell-biological and paleoceanographic insights. Environ. Microbiol. 12, 2107-2119 doi:10.1111/j.1462-2920.2009.02073.x

Bernhard, J. M., Martin, J. B., Rathburn, A. E., 2010b. Combined carbonate carbon isotopic and cellular ultrastructural studies of individual benthic foraminifera: 2. Toward an understanding of apparent disequilibrium in hydrocarbon seeps. Paleoceanography 25, PA4206, doi:10.1029/2010PA001930

Bernhard, J. M., Edgcomb, V. P., Visscher, P. T., McIntyre-Wressnig, A., Summons, R., Bouxsein, M. L., Louis, L., Jeglinski, M., 2013. Insights into foraminiferal influences on microfabrics of microbialites at Highborne Cay, Bahamas. Proc. Natl Acad. Sci. USA 110, 9830-9834. doi: 10.1073/pnas.1221721110

Briguglio, A., Metscher, B., Hohenegger, J., 2011. Growth rate biometric quantification by X-ray microtomography on larger benthic foraminifera: three-dimensional measurements push nummulitids into the fourth dimension. Turkish J. Earth Sci. 20, 683-699. doi:10.3906/yer-0910-44

Briguglio, A, Hohenegger, J., Less, G., 2013. Paleobiological applications of three-dimensional biometry on larger benthic foraminifera: a new route of discoveries. J. Foramin. Res. 43, 72-87. doi: 10.2113/gsjfr.43.1.72

Carpenter, K. J., Weber, P. K., Lee Davisson, M., Pett-Ridge, J., Haverty, M. I., Keeling, P.J., 2013. Correlated SEM, FIB-SEM, TEM, and NanoSIMS imaging of microbes from the hindgut of a lower termite: methods for in situ functional and ecological studies of uncultivable microbes. Microsc. Microanal. 19, 1490-1501. doi: $10.1017 /$ S1431927613013482

Dahlgren, L., 1967a. On the ultrastructure of the gamontic nucleus and the adjacent cytoplasm of the monothalamous foraminifer Ovammina opaca Dahlgren. Zool. Bidrag, Uppsala Bd 37, 77-112.

Dahlgren, L., 1967b. On the nuclear distribution of RNA and DNA and on the ultrastructure of nuclei and adjacent cytoplasm of the foraminifers Hippocrepinella alba Heron-Allen and Earland Globobulimina turgida (Bailey). Zool. Bidrag, Uppsala Bd 37, 113-138.

Ferrández Cañadell, C., 2002. Multicellular-like compartmentalization of cytoplast in fossil larger foraminifera. Lethaia 35, 121-130 doi: 10.1111/j.1502-3931.2002.tb00073.x

Ferrández Cañadell, C., Briguglio, A., Hohenegger, J., Woger, J., 2014. Test fusion in adult foraminifera: A review with new observations of an Early Eocene Nummulites 
specimen. J. Foramin. Res. 44, 316-324 doi: 10.2113/gsjfr.44.3.316

Finzi-Hart, J. A., Pett-Ridge, J., Weber, P. K., Popa, R., Fallon, S. J., Gunderson, T., Hutcheon, I. D., Nealson, K. H., Capone, D. G., 2009. Fixation and fate of $\mathrm{C}$ and $\mathrm{N}$ in the cyanobacterium Trichodesmium using nanometer-scale secondary ion mass spectrometry. Proc. Natl Acad. Sci. USA 106, 6345-6350. doi: 10.1073/pnas.0810547106

Francis, C. A., Beman, J. M., Kuypers, M. M. M., 2007. New processes and players in the nitrogen cycle: the microbial ecology of anaerobic and archaeal ammonia oxidation. The ISME J. 1, 19-27. doi:10.1038/ismej.2007.8

Geslin, E., Heinz P., Hemleben, C., Jorissen, F. J., 2004. Migratory response of deep-sea benthic foraminifera to variable oxygen conditions: laboratory investigations. Mar. Micropaleontol. 53: 227-243. doi: 10.1016/j.marmicro.2004.05.010

Glud, R. N., Wenzhoefer, F., Tengberg, A., Middelboe, M., Oguri, K., Kitazato, H., 2005. Distribution of oxygen in surface sediments from central Sagami Bay, Japan: In situ measurements by microelectrodes and planar optodes. Deep-Sea Res. PT I, 52, 1974-1987 doi:10.1016/j.dsr.2005.05.004

Glud, R. N., Thamdrup, B., Stahl, H., Wenzhoefer, F., Glud, A., Nomaki, H., Oguri, K., Revsbech, N. P., Kitazato, H., 2009. Nitrogen cycling in a deep ocean margin sediment (Sagami Bay, Japan). Limnol. Oceanogr. 54, 723-734 doi: 10.4319/10.2009.54.3.0723

Goldstein, S. T., Richardson, A. E., 2002. Comparison of test and cell body ultrastructure in three modern allogromiid foraminifera: application of high pressure freezing and freeze substitution. J. Foramin. Res. 32, 375-383.

Goldstein, S. T., Richardson, A. E., submitted. Fine structure of the foraminifer Haynesina germanica (Ehrenberg) and its sequestered chloroplasts. Mar. Micropaleontol.

Gross, O., 2000. Influence of temperature, oxygen and food availability on the migrational activity of bathyal benthic foraminifera: evidence by microcosm experiments. Hydrobiologia. 426, 123-137.

Hanaichi, T., Sato, T., Iwamoto, T., Malavasi-yamashiro, J., Hoshino, M., Mizuno, N., 1986. A stable lead by modification of Sato method. J. Electron. Microsc. 35, 304-306.

Hayat, M. A., 2000. Principals and techniques of electron microscopy: biological applications ( $4^{\text {th }}$ edition). 564pp. Cambridge University Press, Cambridge, UK.

Hayward, B. W., Holzmann, M., Grenfell, H. R., Pawlowski, J., Triggs, C. M., 2004. Morphological distinction of molecular types in Ammonia - towards a taxonomic revision of the world's most commonly misidentified foraminifera. Mar. Micropaleontol. 50, 237-271.

Hedley, R. H., Parry, D. M., Wakefield, J. St. J., 1967. Fine structure of Sphepheardella taeniformis (Foraminifera; Protozoa). J. R. Microsc. Soc. 87, 445-456. 
Heinz, P. 1999. Response of deep-sea benthic foraminifera to simulated phytodetritus pulses under laboratory conditions. Tübinger Mikropaläontologische Mitteilungen 20, 126 pp., Tübingen.

Heinz, P., Kitazato, H., Schmiedl, G., Hemleben, C., 2001. Response of deep-sea benthic foraminifera from the Mediterranean Sea to simulated phytoplankton pulses under laboratory conditions. J. Foramin. Res. 31, 210-227.

Hohenegger, J., Briguglio, A., 2012. Axially oriented sections of nummulitids: a tool to interpret larger benthic foraminiferal deposits. J. Foramin. Res. 42, 145-153. doi:10.2113/gsjfr.42.2.134

Holzmann, M., 2000. Species concept in foraminifera: Ammonia as a case study. Micropaleontology 46, 21-37.

Hoppe, P., Cohen, S., Meibom, A., 2013. NanoSIMS: Technical aspects and applications in cosmochemistry and biological geochemistry. Geostand. Geoanal. Res. 37:111-154. doi: 10.1111/j.1751-908X.2013.00239.x

Hottinger, L., 2000. Functional morphology of benthic foraminiferal shells, envelopes of cells beyond measure. Micropaleontology 46 (suppl 1), 57-86.

Iwasaki, S., Kimoto, K., Sasaki, O., Kano, H., Honda, M. C., Okazaki, Y., 2015. Observation of the dissolution process of Globigerina bulloides tests (planktic foraminifera) by X-ray microcomputed tomography. Paleoceanography 30, 317-331. doi: 10.1002/2014PA002639

Jauffrais, T., Jesus, B., Metzger, E., Mouget, J. L., Jorissen, F., Geslin, E., 2016. Effect of light on photosynthetic efficiency of sequestered chloroplasts in intertidal benthic foraminifera (Haynesina germanica and Ammonia tepida). Biogeosciences. 13, 2715-2726. doi:10.5194/bg-13-2715-2016

Jauffrais, T., Jesus, B., Meleder, V., Geslin E., 2017. Functional xanthophyll cycle and pigment content of a kleptoplastic benthic foraminifer: Haynesina germanica. PLoS ONE 12: e0172678. doi:10.1371/journal.pone.0172678

Johnstone, H. J. H., M. Schulz, S. Barker, Elderfield, H., 2010. Inside story: An X-ray computed tomography method for assessing dissolution in the tests of planktonic foraminifera. Mar. Micropaleontol., 77, 58-70. doi:10.1016/j.marmicro.2010.07.004

Jorissen, F. J., de Stigter, H. C., Widmark, J. G. V., 1995. A conceptual model explaining benthic foraminiferal microhabitats. Mar. Micropaleontol. 26, 3-15.

Khalifa, G. M., Kirchenbuechler, D., Koifman, N., Kleinerman, O., Talmon, Y., Elbaum, M., Addadi, L., Weiner, S., Erez, J., 2016. Biomineralization pathways in a foraminifer revealed using a novel correlative cryo-fluorescence-SEM-EDS technique. J Struct Biol. 196, 155-163. doi: 10.1016/j.jsb.2016.01.015.

Koho, K. A., Piña-Ochoa, E., Geslin, E., Risgaard-Petersen, N., 2011. Vertical migration, nitrate uptake and denitrification: Survival mechanisms of foraminifers 
(Globobulimina turgida) under low oxygen conditions. FEMS Microbiol. Ecol. 75, 273-283, doi:10.1111/j.1574-6941.2010.01010.x

Koho, K. A., LeKieffre, C., Nomaki, H., Salonen, I., Geslin, E., Mabilleau, G., Jensen, L. H. S., Reichart, G. J., in revision. Changes in ultrastructural features of the foraminifera Ammonia spp. in response to anoxic conditions: field and laboratory observations. Mar. Micropaleontol. This issue.

Kopp, C., Domart-Coulon, I., Escrig, S., Humbel, B. M., Hignette, M., Meibom, A., 2015. Subcellular investigation of photosynthesis-driven carbon assimilation in the symbiotic reef coral Pocillopora damicornis. mBio 6, e02299-14. doi:10.1128/mBio.02299-14.

Kremer, B. P., Schmaljohann, R., Röttger, R., 1980. Features and nutritional significance of photosynthates produced by unicellular algae symbiotic with larger foraminifera. Mar. Ecol. Prog. Ser, 2, 225-228.

Larabell, C. A., Le Gros, M. A., 2004. X-ray tomography generates 3-D reconstructions of the yeast, Saccharomyces cerevisiae, at 60-nm resolution. Mol. Biol. Cell 15:957-962 doi:10.1091/mbc.E03-07-0522

Lee, J. J. Hallock, P., 1987. Algal symbiosis as the driving force in the evolution of larger foraminifera. Ann. N. Y. Acad. Sci. 503, 330-347, doi: 10.1111/j.1749-6632.1987.tb40619.x

Lee, J. J., Anderson O. R., 1991. Symbiosis in Foraminifera, p.157-220. In J. J. Lee and O. R. Anderson [eds.], Biology of Foraminifera. Academic Press.

Le Gros, M. A., McDermott, G., Larabell, C. A., 2005. X-ray tomography of whole cells. Curr. Opin. Struc. Biol. 15: 593-600 doi:10.1016/j.sbi.2005.08.008

LeKieffre, C., Spangenberg, J. E., Mabilleau, G., Escrig, S., Meibom, A., Geslin, E., 2017. Surviving anoxia in marine sediments: The metabolic response of ubiquitous benthic foraminifera (Ammonia tepida). PLoS ONE. 12(5): e0177604. doi: 10.1371/journal.pone.0177604

LeKieffre, C., Bernhard, J. M., Mabilleau, G., Filipsson, H. L., Meibom, A., Geslin, E., submitted. An overview of cellular ultrastructure in benthic foraminifera: New observations in the context of existing literature. Mar. Micropal.

Leutenegger, S., Hansen, H. J., 1979. Ultrastructural and Radiotracer studies of pore function in foraminifera. Mar. Biol. 54, 11-16.

Libes, S. M., 2009. Introduction to marine biogeochemistry, 2nd edition. Academic Press.

Lucas, M. S., Guenthert, M., Gasser, P., Lucas, F., Wepf, R., 2014. Correlative 3D imaging: CLSM and FIB-SEM tomography using high-pressure frozen, freeze-substituted biological samples. Methods Mol. Biol. 1117:593-616. doi: 10.1007/978-1-62703-776-1_26

Lloyd, K. G., Albert, D. B., Biddle, J. F., Chanton, J. P., Pizarro, O., Teske, A., 2010. Spatial 
structure and activity of sedimentary microbial communities underlying a Beggiatoa spp. mat in a Gulf of Mexico hydrocarbon seep. PLoS ONE 5(1): e8738. doi:10.1371/journal.pone.0008738

Martin, J. B., Bernhard, J. M., Curtis, J., Rathburn, A. E., 2010. Combined carbonate carbon isotopic and cellular ultrastructural studies of individual benthic foraminifera: Method description. Paleoceanography 25, PA2211, doi:10.1029/2009PA001846

Metzger, E., Thibault de Chanvalon, A., Cesbron, F., Barbe, A., Launeau, P., Jézéquel, D., Mouret, A., 2016. Simultaneous nitrite/nitrate imagery at millimeter scale through the water-sediment interface. Environ. Sci. Technol. 50, 8188-8195. doi: 10.1021/acs.est.6b00187

Micheva, K. D., Smith, S. J., 2007. Array tomography: a new tool for imaging the molecular architecture and ultrastructure of neural circuits. Neuron 55, 25-36. doi:10.1016/j.neuron.2007.06.014

Moodley, L., van der Zwaan, G. J., Rutten, G. M. W., Boom, R. C. E, Kempers, A. J., 1998. Subsurface activity of benthic foraminifera in relation to porewater oxygen content: laboratory experiments. Mar. Micropaleontol. 34, 91-106.

Moor, H., 1987. Theory and practice of high pressure freezing. In Cryotechniques in Biological Electron Microscopy [Steinbrecht, R. A., Zierold, K. eds.] Springer-Verlag, Berlin, p. 175-191.

Murray, J. W., 1996. Ecology and Applications of Benthic Foraminifera. Cambridge University Press.

Musat, N., Stryhanyuk, H., Bombach, P., Adrian, L., Audinot, J.-N., Richnow, H. H., 2014. The effect of FISH and CARD-FISH on the isotopic composition of ${ }^{13} \mathrm{C}$ - and ${ }^{15} \mathrm{~N}$-labeled Pseudomonas putida cells measured by nanoSIMS. Syst. Appl. Microbiol. 37, 267-276. doi:10.1016/j.syapm.2014.02.002

Narayan, K., Subramaniam, S., 2015. Focused ion beams in biology. Nature Methods 12 (11), 1021-1031. doi:10.1038/nmeth.3623

Nomaki, H., Heinz, P., Hemleben, C., Kitazato, H., 2005. Behaviors and responses of deep-sea benthic foraminifera to freshly supplied organic matter: Laboratory feeding experiments in microcosm environments. J. Foramin. Res. 35, 103-113. doi: $10.2113 / 35.2 .103$

Nomaki, H., Chikaraishi, Y., Tsuchiya, M., Toyofuku, T., Ohkouchi, N., Uematsu, K., Tame, A., Kitazato, H., 2014. Nitrate uptake by foraminifera and use in conjunction with endobionts under anoxic conditions. Limnol. Oceanogr. 59, 1879-1888. doi: 10.4319/10.2014.59.6.1879

Nomaki, H., Toyofuku, T., Tsuchiya, M., Matsuzaki, T., Uematsu, K., Tame, A., 2015. Three-dimensional observation of foraminiferal cytoplasmic morphology and internal structures using uranium-osmium staining and micro-X-ray computed tomography. 
Mar. Micropaleontol. 121, 32-40. doi:10.1016/j.marmicro.2015.09.003

Nomaki, H., Bernhard, J. M., Ishida, A., Tsuchiya, M., Uematsu, K., Tame, A., Kitahashi, T., Takahata, N., Sano, Y., Toyofuku, T., 2016. Intracellular isotope localization in Ammonia sp. (Foraminifera) of oxygen-depleted environments: results of nitrate and sulfate labeling experiments. Front. Microbiol., 7, Article 163, doi: $10.3389 /$ fmicb. 2016.00163

Pernice, M., Meibom, A., Van Den Heuvel, A., Kopp, C., Domart-Coulon, I., Hoegh-Guldberg, O., Dove, S., 2012. A single-cell view of ammonium assimilation in coral-dinoflagellate symbiosis. The ISME J., 6, 1314-1324.

Polerecky, L., Adam, B., Milucka, J., Musat, N., Vagner, T., Kuypers, M. M. M., 2012. Look@NanoSIMS - a tool for the analysis of nanoSIMS data in environmental microbiology. Environ. Microbiol. 14, 1009-1023. doi:10.1111/j.1462-2920.2011.02681.x

Rieder, C. L., Bowser, S. S., 1987. Correlative light and electron microscopy on the same epoxy section. In: Hayat, M.A. (Ed.), Correlative Microscopy in Biology: Instrumentation and Methods. Academic Press, Orlando, pp. 249-277.

Speijer, R. P., Loo, D. V., Masschaele, B., Vlassenbroeck, J., Cnuddle, V., Jacobs, P., 2008. Quantifying foraminiferal growth with high-resolution X-ray computed tomography: New opportunities in foraminiferal ontogeny, phylogeny, and paleoceanographic applications. Geosphere 4, 760-763. doi:10.1130/GES00176.1

Thibault de Chanvalon, A., Metzger, E., Mouret, A., Cesbron, F., Knoery, J., Rozuel, E., Launeau, P., Nardelli, M. P., Jorissen, F. J., Geslin, E., 2015. Two-dimensional distribution of living benthic foraminifera in anoxic sediment layers of an estuarine mudflat (Loire estuary, France). Biogeosciences, 12, 6219-6234. doi:10.5194/bg-12-6219-2015

Travis, J. L., Bowser, S. S., 1986. A new model of reticulopodial motility and shape: Evidence for a microtubule-based motor and an actin skeleton. Cell. Motil. Cytoskeleton 6, 2-14.

Tsuchiya, M., Toyofuku, T., Uematsu, K., Bruchert, V., Collen, J., Yamamoto, H., Kitazato, H., 2015. Cytologic and genetic characteristics of endobiotic bacteria and kleptoplasts of Virgulinella fragilis (Foraminifera). J. Eukaryot. Microbiol. 62, 454-469. doi:10.1111/jeu. 12200

Yabuki, A., Chao, E. E., Ishida, K., Cavalier-Smith, T., 2012. Microheliella maris (Microhelida ord. n.), an ultrastructurally highly distinctive new axopodial protist species and genus, and the unity of phylum Heliozoa. Protist 163, 356-388. doi:10.1016/j.protis.2011.10.001 
949 Yabuki, A., Eikrem, W., Takishita, K., Patterson, D. J., 2013. Fine structure of Telonema $950 \quad$ subtilis Griessmann, 1913: A flagellate with a unique cytoskeletal structure among 951 eukaryotes. Protist 164, 556-569. doi:10.1016/j.protis.2013.04.004

952

953

954 


\section{Figure legends}

Figure 1 (view in color). Light micrographs of Buliminella tenuata in living position in non-seep sediments. A. Reflected light image showing excised portion of FLEC section that includes the foraminifer (white arrowhead). The black marking (white ${ }^{\wedge}$ ) is a permanent marker to guide in locating the specimen during excision. Note that the top of the sediment in the image is not the sediment-seawater interface (see text). B. LSCM micrograph showing the fluorescent specimen in sediments. Note the vacuolated nature of the cytoplasm, relatively empty ultimate chamber and veil of fluorescent material on the test exterior (arrows). sg1 and sg2 mark particular sediment grains that are also visible in C. C. Transmitted light micrograph of a thick section stained with toluidine blue, showing the specimen after sectioning. Note the holes where the sediment grains $(\operatorname{sg} 1, \operatorname{sg} 2)$ occurred. $t=$ test. $*=$ open pore space adjacent to aperture. Scales: $\mathrm{A}=500 \mu \mathrm{m} ; \mathrm{B}, \mathrm{C}=100 \mu \mathrm{m}$.

Figure 2. Transmission electron micrographs of $B$. tenuata collected from non-seep sediments. A. Overview of chamber periphery showing cytoplasm with large vacuoles (v) and degradation vacuoles $(\mathrm{dv})$. po $=$ pores; $\mathrm{t}=$ location of former test; white arrowhead = prokaryote in degradation vacuole. B. Internal edge of chamber showing mitochondria $(\mathrm{m})$ and degradation vacuoles. $\mathrm{g}=$ Golgi. C. Periphery of chamber, tangentially through pores, showing mitochondria associated with pores and Golgi. ol= organic lining; eo= electron-opaque body; black arrow $=$ mitochondrial double membrane. Inset: cross section through pore showing preservation of fibrous material.

D. Chamber periphery showing mitochondria and Golgi. E. Peroxisomes (p) complexed with endoplasmic reticulum (er), showing darker core (inset). F,G. Images taken outside the foraminiferan test, which existed in the light-colored spaces. Areas of interest are the blebs $\left(^{*}\right)$, which likely were reticulopods that produced the fluorescence on the test exterior in Fig. 1B. Scales: A $=2 \mu \mathrm{m} ; \mathrm{B}, \mathrm{G}=1 \mu \mathrm{m}$; $\mathrm{C}-\mathrm{F}=0.5 \mu \mathrm{m}$.

Figure 3 (view in color). Light micrographs of an agglutinated biserial foraminifer in living position in seep sediments. A, B. Paired images showing specimens in life position in sediments preserved with FLEC. A. Double exposure micrograph of epifluorescence and reflected light showing foraminifer in life position $1.3 \mathrm{~mm}$ below the sediment-water interface and close to a juvenile bivalve $(+)$. White and black arrow $=$ cross section of a calcareous foraminifer. B. Epifluorescence micrograph revealing microbes (fluorescent items including prokaryotes and/or eukaryotes; some are labeled with white arrowheads) shown in this image.

991 Note the calcareous foraminifer noted in A is not fluorescent (i.e., dead). C. LSCM micrograph showing the vacuolated nature of the cytoplasm, nucleus (black*), relatively empty ultimate 
993

994

995

996

997

998

999

1000

1001

1002

1003

1004

1005

1006

1007

1008

1009

1010

1011

1012

1013

1014

1015

1016

1017

1018

1019

1020

1021

1022

1023

1024

1025

1026

1027

1028

1029

1030

(youngest) chamber (\#), feeding bolus or reticulopodial trunk near the aperture (white arrow), and mineral grains in test (white *). Note the fine filaments in the adjacent sediments (white arrowheads). $\mathrm{t}=$ test. Scales: $\mathrm{B}=1 \mathrm{~mm}(\mathrm{~A}=$ same magnification as $\mathrm{B}) ; \mathrm{C}=200 \mu \mathrm{m}$.

Figure 4. Transmission Electron Micrographs of a biserial agglutinated foraminifer collected from seep sediments. A. Overview, including portion of cell periphery with organic lining (ol), showing cytoplasm with large empty vacuoles (v) and some appearing to include 1-2 prokaryotes (black arrows) and digestive vacuoles $(\mathrm{dv})$. Fractured mineral grains from test $(\mathrm{t})$ are evident; empty (white) space is space formerly occupied by sediment grains (i.e., foraminiferal test). B. Overview showing prokaryotes (arrows) occurring in the lumen between organic lining and interior surface of test. C. Area showing what are interpreted to be mitochondria $(\mathrm{m})$, along with vacuoles and organic lining. Some mitochondria have faintly visible double membranes (white arrowhead). D. More mitochondria with faint double membranes and cristae (white arrowheads), along with peroxisomes (p) and endoplasmic reticulum (er). Scales: $\mathrm{A}, \mathrm{B}=2 \mu \mathrm{m} ; \mathrm{C}=1 \mu \mathrm{m} ; \mathrm{D}=0.5 \mu \mathrm{m}$.

Figure 5 (view in color). Micro-X-ray CT slice images of Ammonia sp. (phylotype T6) incubated under dysoxic condition. A. Reconstructed micro-X-ray CT image of the Ammonia sp. White arrowhead shows a depressed cytoplasm in the chamber. B. Cross-sectional view of the CT image indicated as b1'-b2' to b1'-b" in A. C. A cross-sectional view from the spiral side. D. A cross-sectional view of the CT image indicated as $d 1$ '-d2' to $d 1$ "'-d2" in A. In the panels $\mathrm{B}, \mathrm{C}$, and $\mathrm{D}$, white indicates more X-ray absorbance, meaning higher electron density. Note that this specimen was sectioned for TEM observation before carrying out the micro-X-ray CT imaging. Scale bars $=100 \mu \mathrm{m}$.

Figure 6 (view in color). Micro-X-ray images of Bolivina spissa collected from the bathyal Sagami Bay. A. Reconstructed micro-X-ray CT image of the Bolivina spissa. B. A view from the aperture side indicated as the arrow $\mathrm{b}$ in A. C. A view from the proloculus side indicated as the arrow c in A. D. A cross-sectional view of the Bolivina spissa indicated as the plane d in A. Many vacuoles (v) and a part of plug (pl) are visible. E. A cross-sectional view of the Bolivina spissa indicated as the plane e in A. In panels D and E, white indicates more X-ray absorbance, meaning higher electron density. Scale bars $=100 \mu \mathrm{m}$.

Figure 7 (view in color). Examples of TEM-NanoSIMS analysis on Ammonia sp. (phylotype T6) incubated under dysoxic conditions. A. Osmium coated semi-thin sections of Ammonia sp. (phylotype T6) on a copper grid. Note that the TEM observations (B, C, D, and E) were carried out before the osmium coating. B. Low-magnification TEM image of the whole specimen. The square marked with $\mathrm{c}$ indicate the area where montage images of TEM were 
1031

1032

1033

1034

1035

1036

1037

1038

1039

1040

1041

1042

1043

1044

1045

1046

1047

1048

1049

1050

1051

1052

1053

1054

1055

1056

1057

1058

1059

1060

1061

1062

1063

1064

1065

1066

1067

1068

made. C. Montage images of TEM which were observed with $\times 3,500$ magnification. The squares marked with $\mathrm{d}$ and e indicate the area where NanoSIMS analysis were performed. D and E. Correlative TEM images and NanoSIMS images on nitrogen mapping $\left({ }^{12} \mathrm{C}^{14} \mathrm{~N}^{-}\right.$count per each pixel) and the ratio of ${ }^{15} \mathrm{~N} /{ }^{14} \mathrm{~N}\left({ }^{12} \mathrm{C}^{15} \mathrm{~N}^{-}\right.$count $/{ }^{12} \mathrm{C}^{14} \mathrm{~N}^{-}$count per each pixel). m: mitochondria, li: lipid droplet, v: vacuole. D: $15 \mu \mathrm{m}$ x $15 \mu \mathrm{m}$. E: $12 \mu \mathrm{m}$ x $12 \mu \mathrm{m}$.

Figure 8 (view in color). Isotopic signal quantification on NanoSIMS images with the software Look@NanoSIMS (Polerecky et al., 2012). The example illustrated in this figure is a quantification of the $\delta^{13} \mathrm{C}$ in the endoplasm of a species of Ammonia sp. (phylotype T6) which was fed with ${ }^{13} \mathrm{C}$-enriched diatoms. A: TEM micrograph of the endoplasm of an Ammonia sp. (phylotype T6) B: Corresponding ${ }^{12} \mathrm{C}^{14} \mathrm{~N}$ NanoSIMS image. C: Overlay of the TEM and ${ }^{12} \mathrm{C}^{14} \mathrm{~N}$ NanoSIMS images following the alignment procedure with the software Look@NanoSIMS; blue: TEM, red: ${ }^{12} \mathrm{C}^{14} \mathrm{~N}$ image. D: Drawing of regions on interest (ROIs) on the overlay image (here the ROIs are diatoms). The ROIs are numbered order from left to right. E: Application of the ROI template on the aligned $\delta^{13} \mathrm{C}$ NanoSIMS image. F: Results compiled in a table by the software, each line corresponds to one ROI: identification (\#i), positions $\mathrm{x}$ and $\mathrm{y}$ of the $\mathrm{ROI}$ central point (Xi and $\mathrm{Yi}$ ), $\delta^{13} \mathrm{C}$ enrichment value (MEANi, here in \%), Poisson error (Poiss_Ei, theoretical precision of the mean), size: diameter in $\mu \mathrm{m}$ (SIZESi) and in pixels (PIXELSi), and classification (here "d" for diatom). d: diatom. Scale bars: $5 \mu \mathrm{m}$.

Figure 9 (view in color). TEM micrographs (left) and corresponding NanoSIMS images (right) of the endoplasm of different foraminiferal species incubated with different sources of isotopes. A. Ammonia sp. (phylotype T6) fed with a ${ }^{13} \mathrm{C}$-enriched diatom biofilm. The ${ }^{13} \mathrm{C}$ signal could be traced in the diatoms ingested inside the foraminiferal endoplasm (for more details see LeKieffre et al. in press). B. Haynesina germanica incubated with $\mathrm{H}^{13} \mathrm{CO}_{3}{ }^{-}$as a source of inorganic carbon. C. Nonionellina labradorica incubated with ${ }^{15} \mathrm{NH}_{4}^{+}$as a source of inorganic nitrogen. D. Ammonia sp. (phylotype T6) incubated with ${ }^{15} \mathrm{NO}_{3}{ }^{-}$as a source of inorganic nitrogen in anoxia. E. Ammonia sp. (phylotype T6) incubated with ${ }^{34} \mathrm{SO}_{4}{ }^{3-}$ as a source of inorganic sulfur in dysoxia. White arrowheads indicate the labeled isotope localization in the foraminiferal cytoplasm and the black arrowheads indicate the corresponding region in the TEM images. $\mathrm{d}$ : diatom, n: nucleus, v: vacuole, c: chloroplast, $\mathrm{m}$ : mitochondria, ob: electron opaque body, eb: elongated body, dv: degradation vacuole.

Supplementary movie 1. Reconstructed 3-D micro-X-ray CT image of Ammonia sp. (phylotype T6), obtained with the Xradia 410 Versa microfocus X-ray CT system. Note that this specimen was sectioned for TEM observation before conducting micro-X-ray CT imaging. The ultimate 3 to 4 chambers look frothy (less densely packed) in comparison to 
1069 other chambers. Among the ultimate 3 to 4 chambers, the outer portions of the chambers 1070 appear denser than the inner portions (closest to the axis of rotation), reflecting what appears 1071 to be more vacuoles nearer the aperture of this species. Particles showing high X-ray 1072 attenuation are (mineral) particles originally attached on the umbilical part outside the calcite 1073 test.

1074

1075 Supplementary movie 2. Reconstructed 3-D micro-X-ray CT image of Bolivina spissa, 1076 obtained with the Xradia 410 Versa microfocus X-ray CT system, showing external surface of 1077 the cytosol, together with large vacuoles.

1079 Supplementary movie 3. Reconstructed 3-D micro-X-ray CT image of the same Bolivina 1080 spissa specimen in Supplementary movie 2, but the obtained image was processed to 1081 visualize the inner structure. In the cross section, plugs separating cytoplasm between 1082 chambers, shown in red (high densities), were clearly observed through the entire cross 1083 section. Note that the color contrast was altered from Supplementary movie 2 to better 1084 illustrate the plugs. 

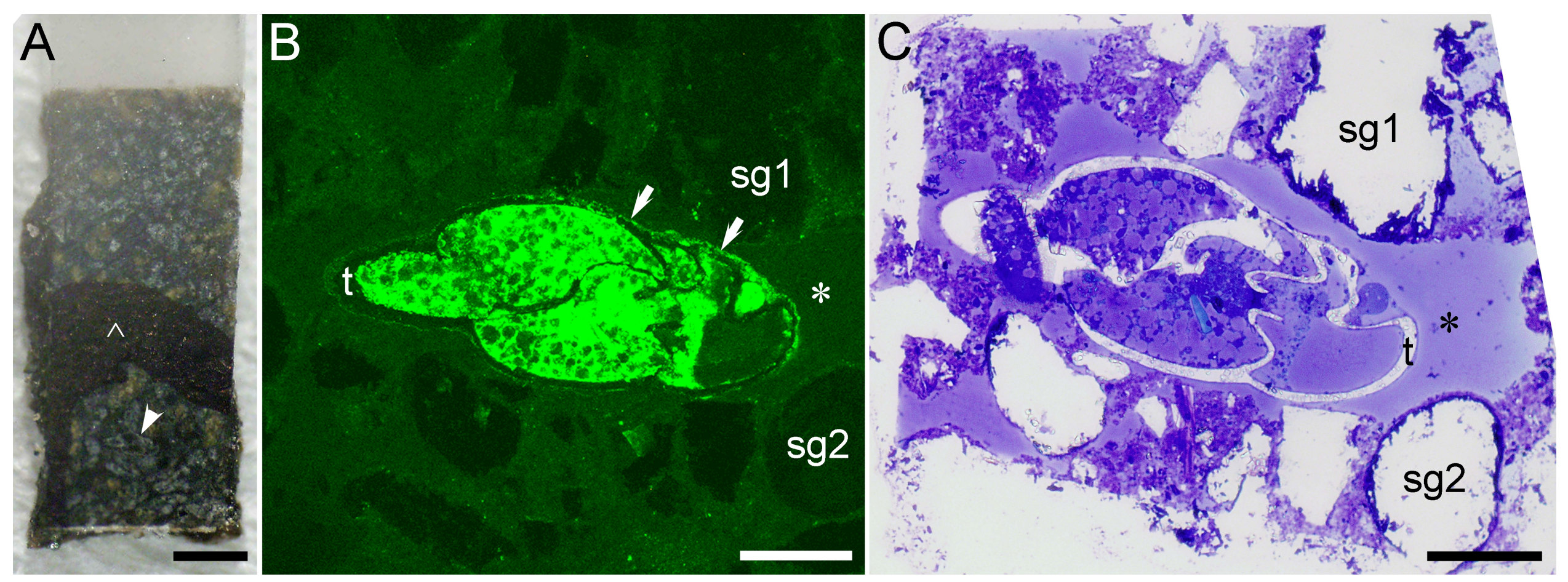


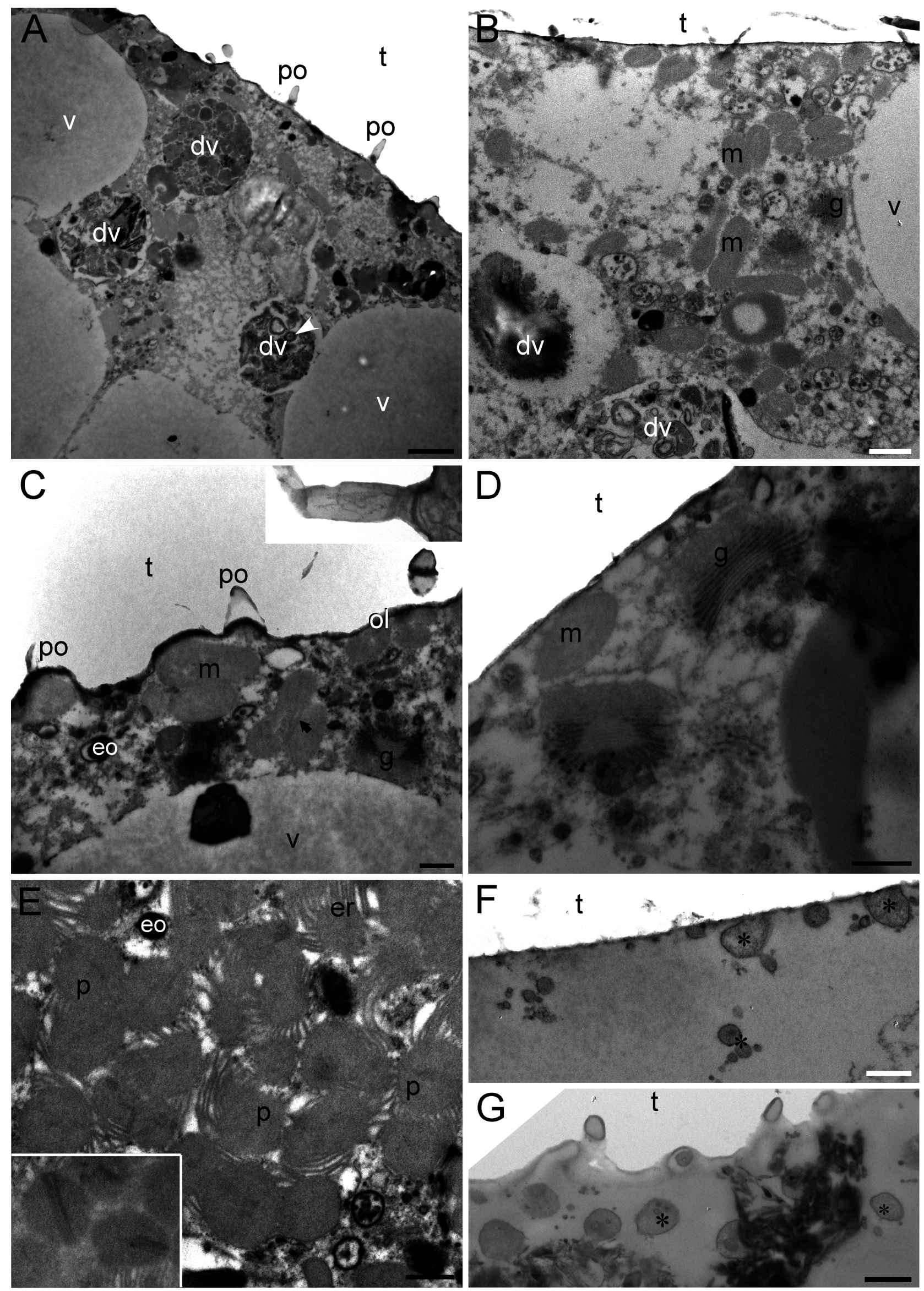



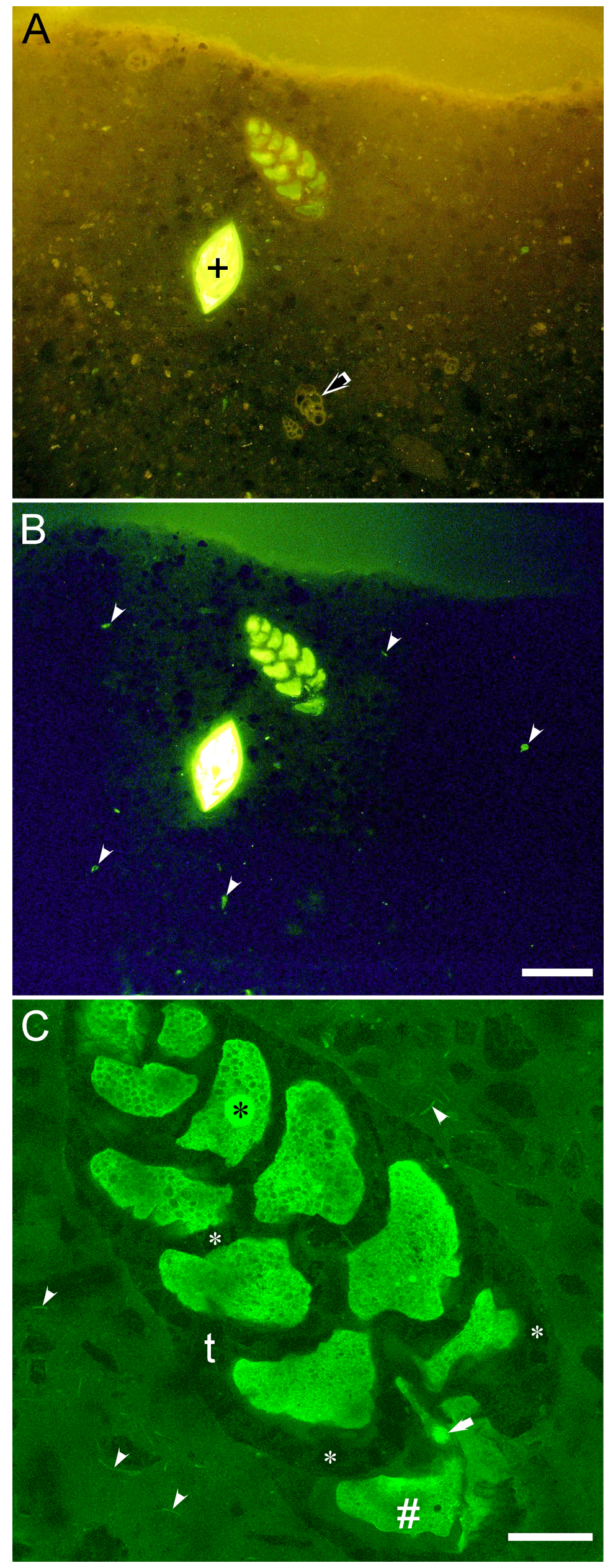


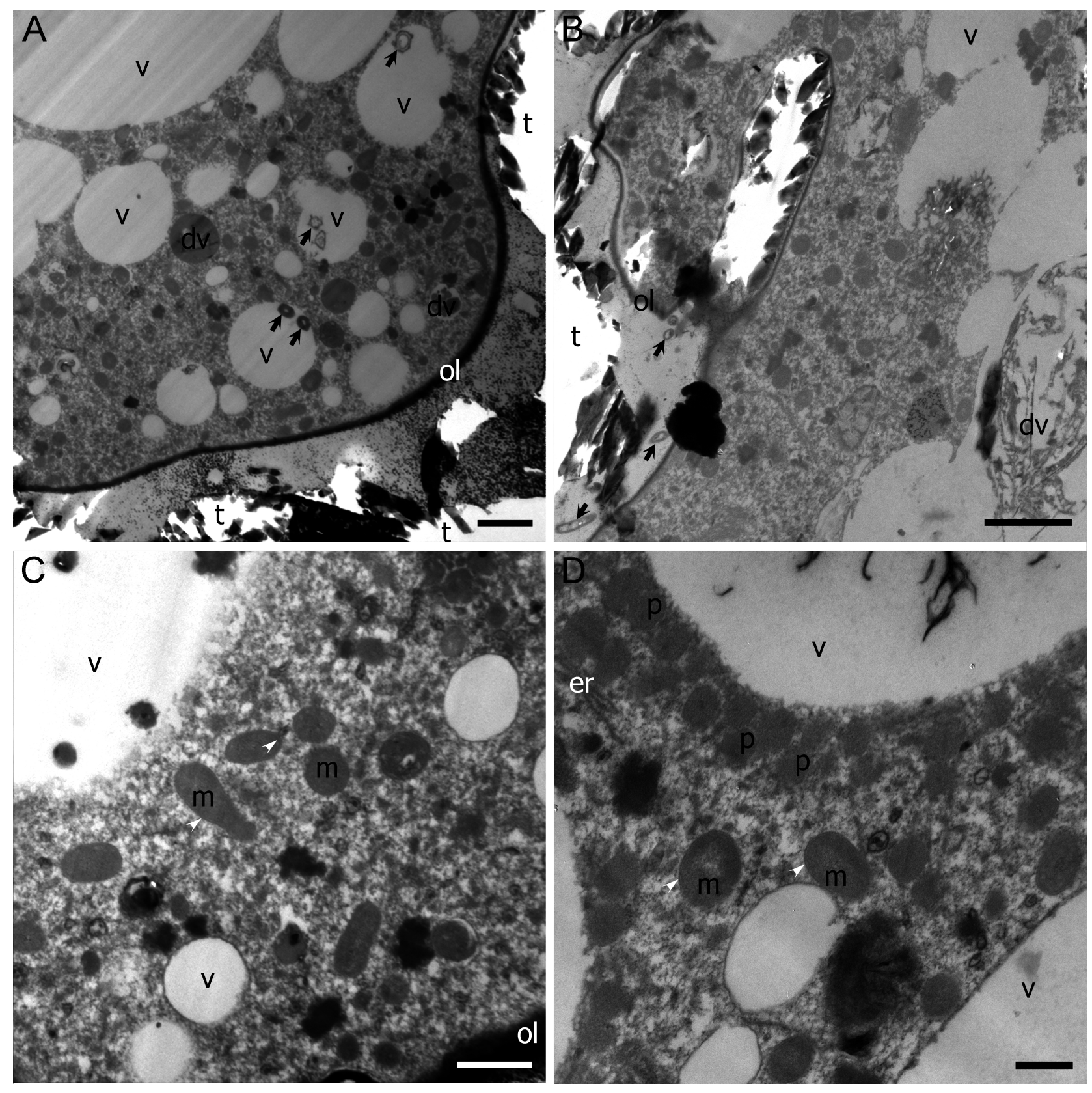




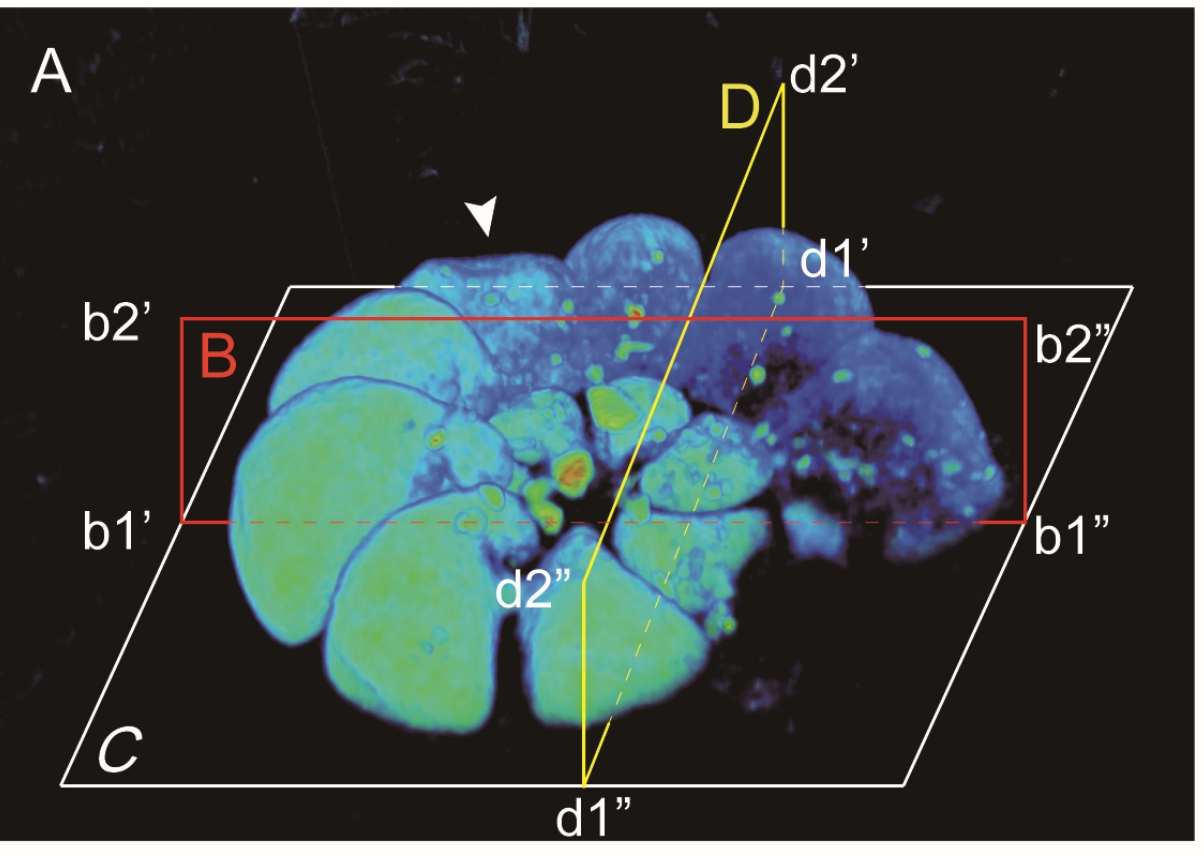

Figure 5
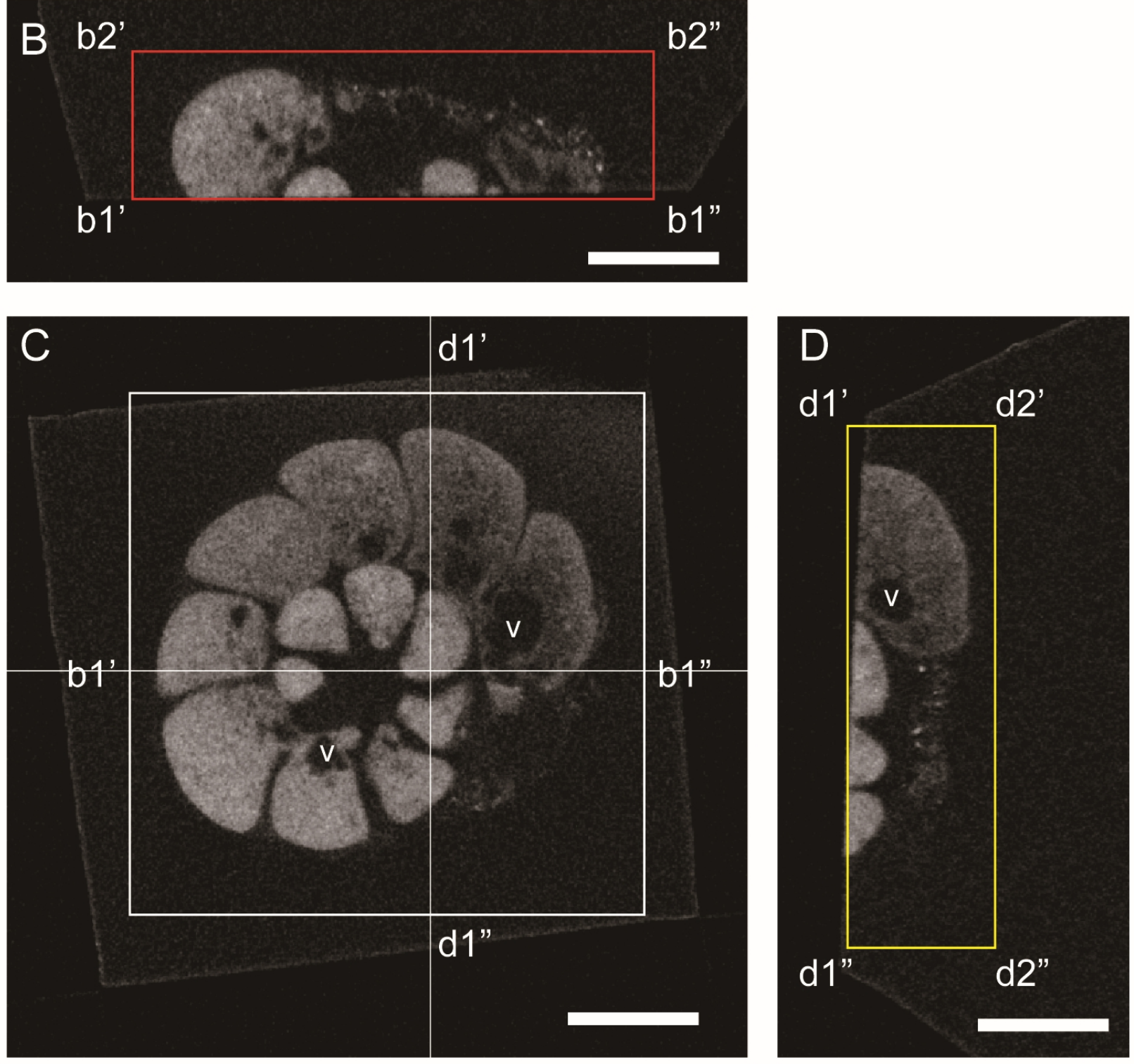
Figure 6

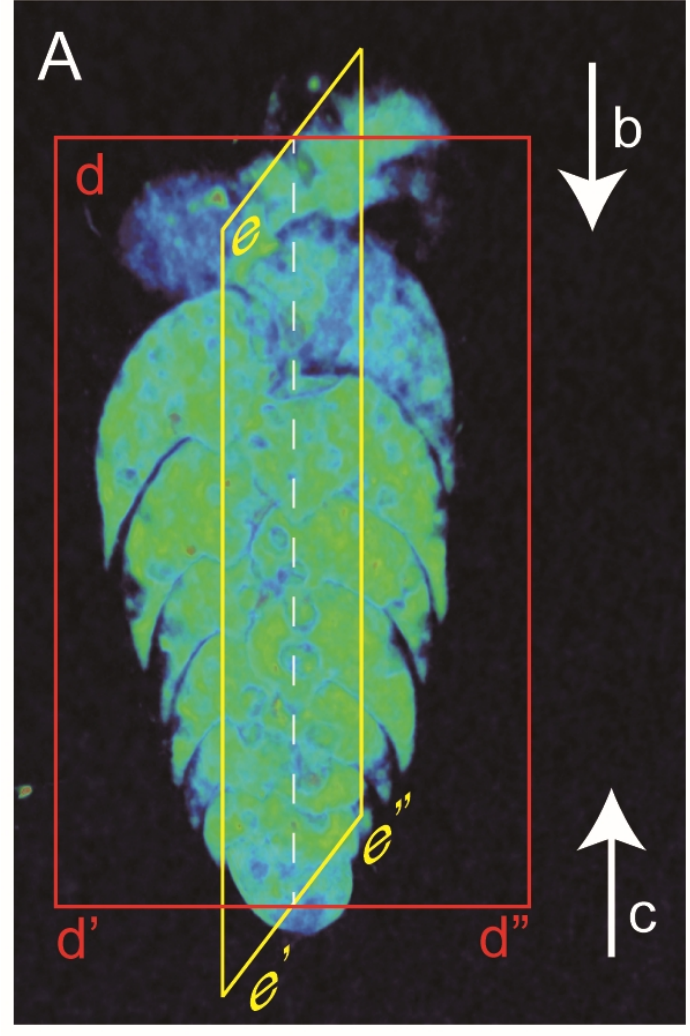

B

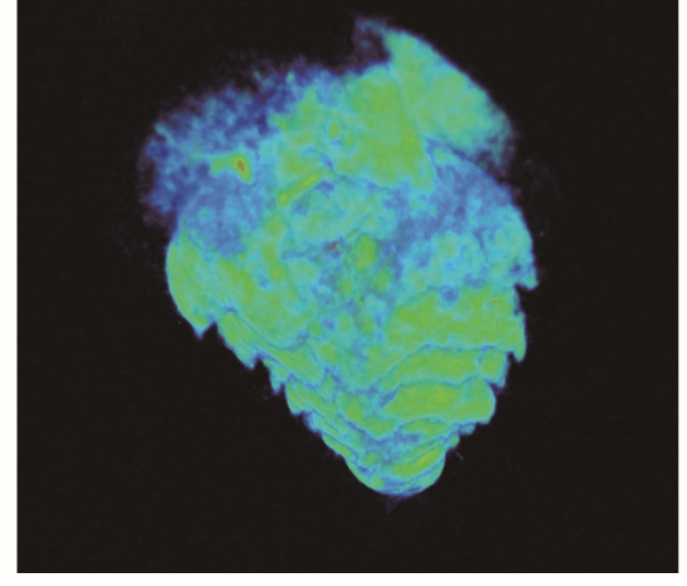

C

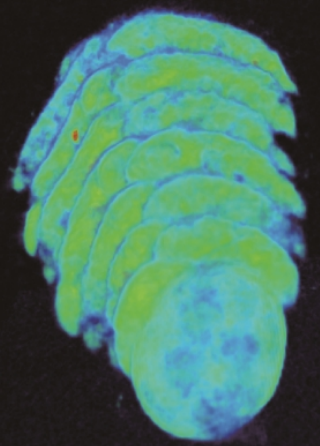

D

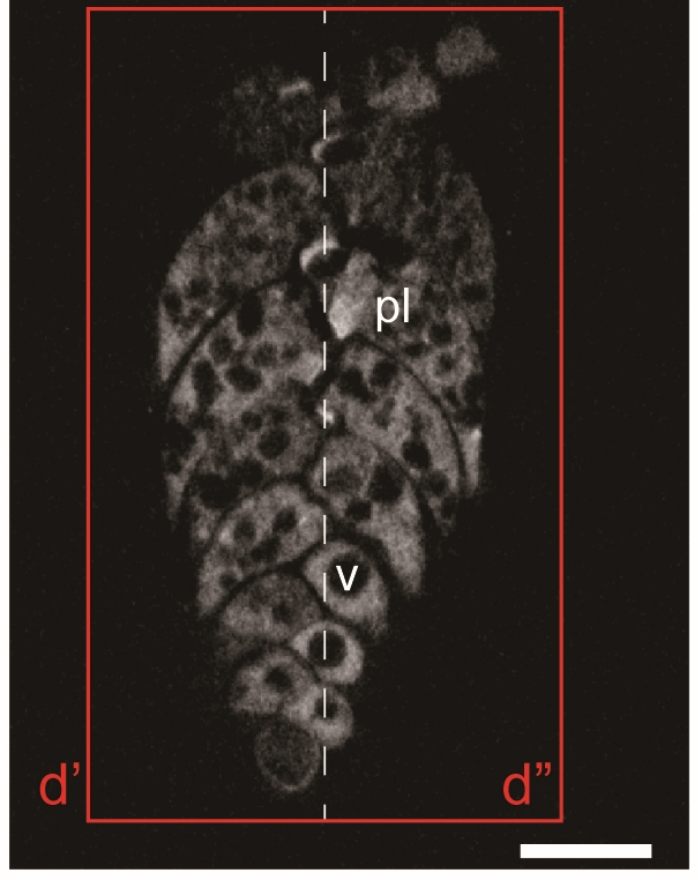

E

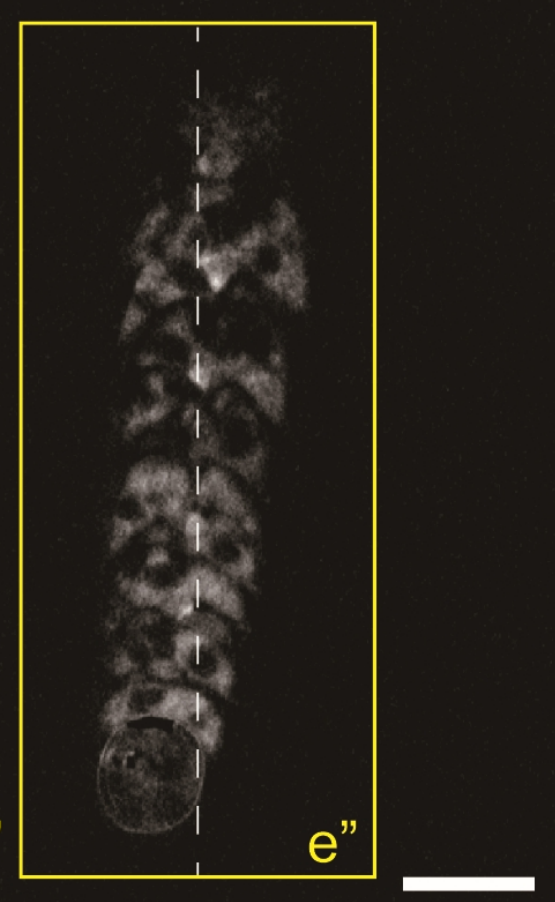




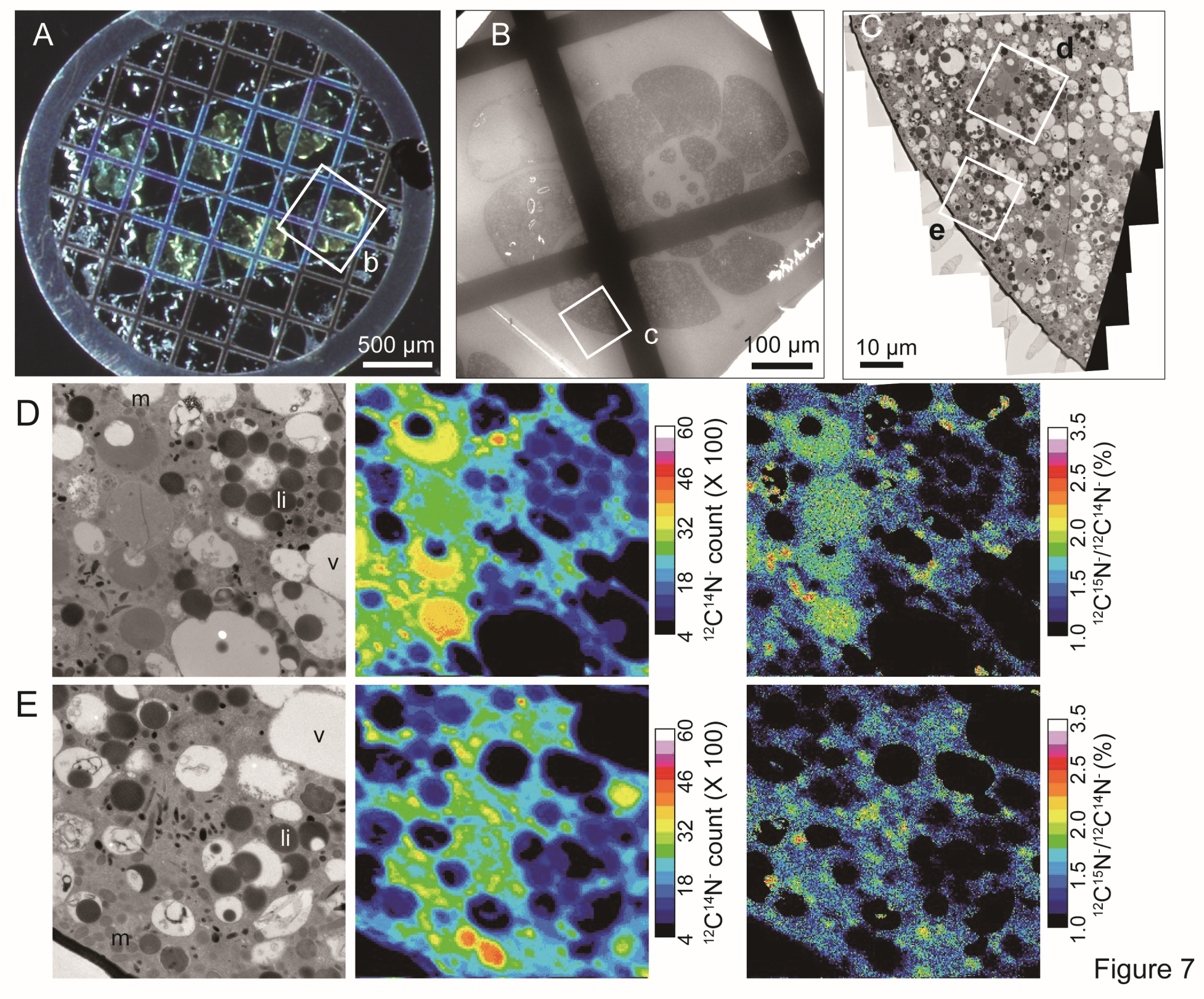




\section{Figure 8}

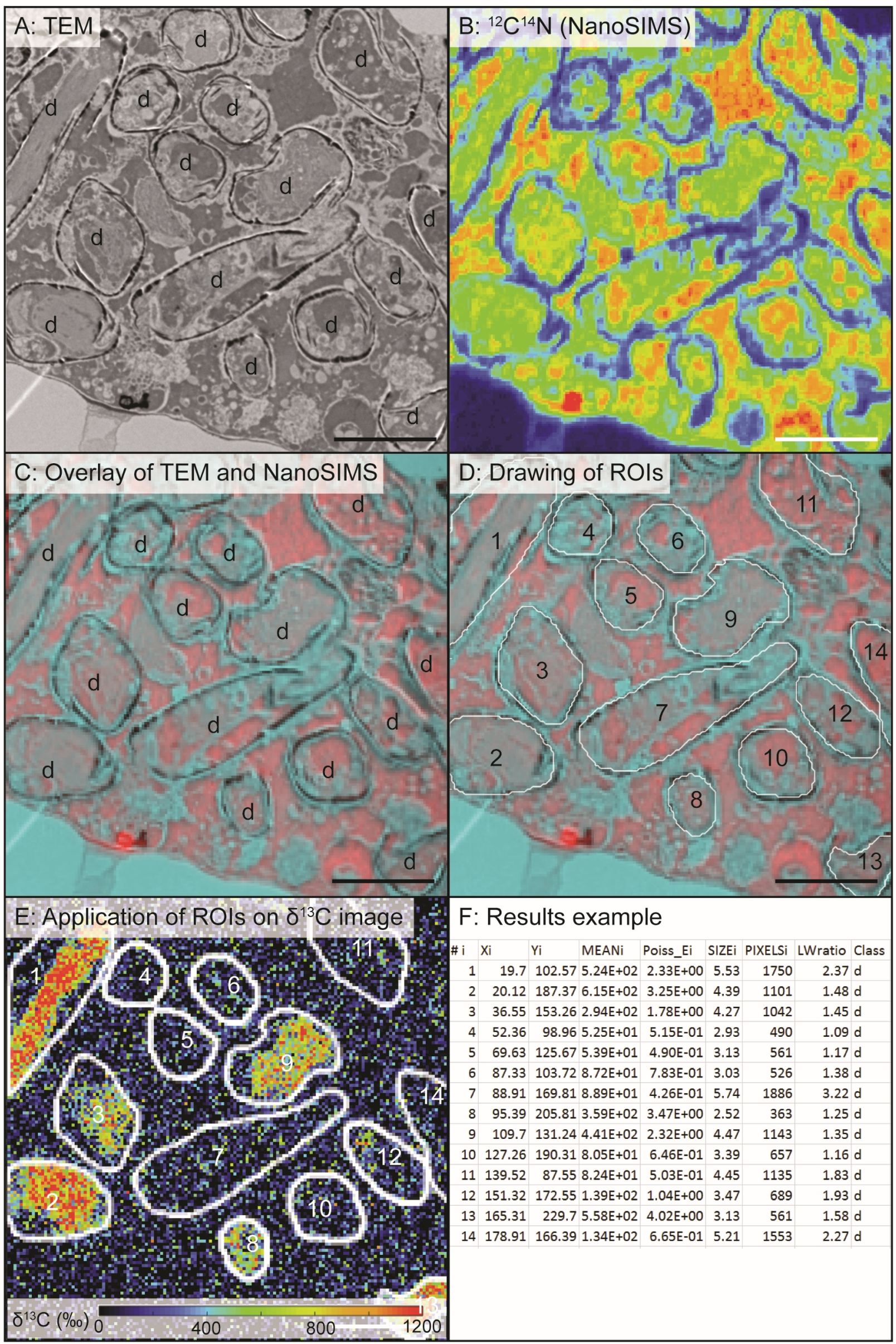


Figure 9

\section{TEM}

A 13

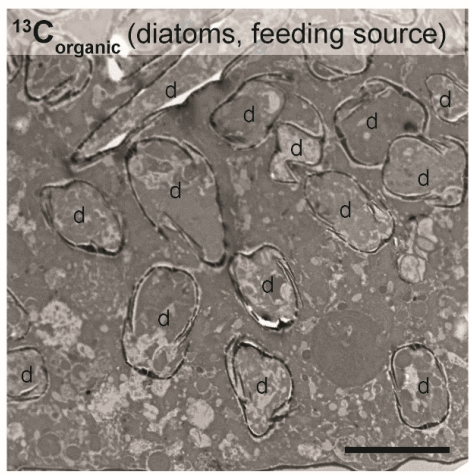

B

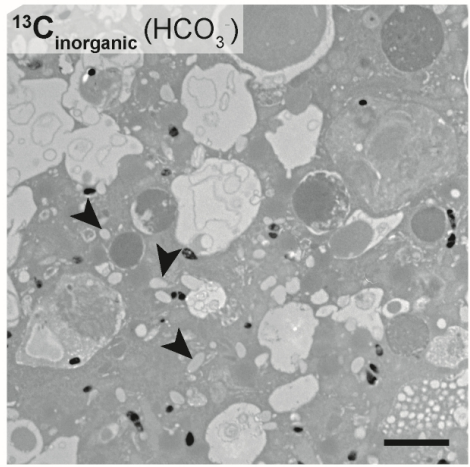

$\mathrm{C} \mathrm{N}$
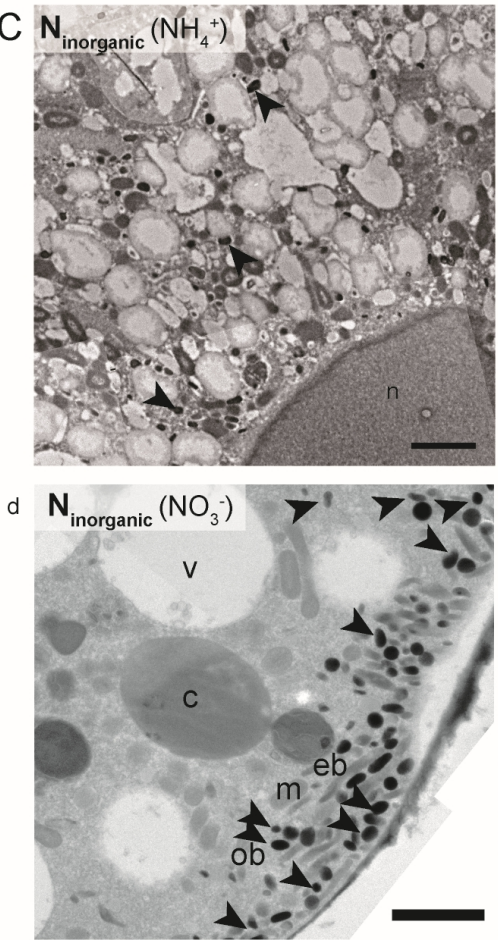

E

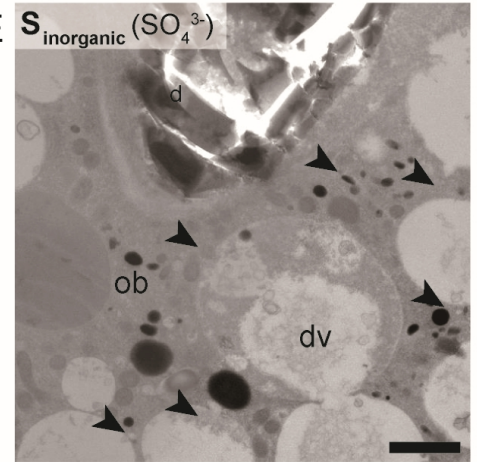

NanoSIMS
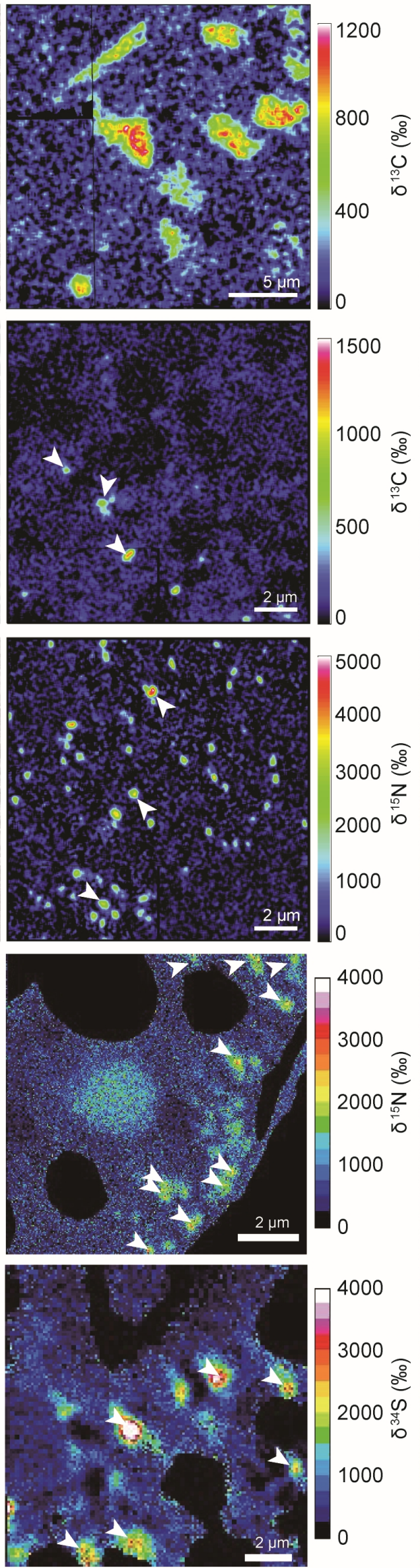
Table 1. Incubation periods and stable isotope labels used for TEM-NanoSIMS analyses.

\begin{tabular}{lll}
\hline Species & Incubation period & Added isotope label \\
\hline Ammonia sp. phytotype $\mathrm{T} 6{ }^{1}$ & $24 \mathrm{~h}$ & ${ }^{13} \mathrm{C}$-enriched diatom biofilm \\
Haynesina germanica $^{1}$ & $16 \mathrm{~h}$ & $\mathrm{NaH}^{13} \mathrm{CO}_{3}$ \\
Nonionellina labradorica $^{1}$ & $7 \mathrm{~h}$ & ${ }^{15} \mathrm{NH}_{4} \mathrm{Cl}$ \\
Ammonia sp. phylotype $\mathrm{T}^{2}$ & $14 \mathrm{~d}$ & $\mathrm{NaH}^{13} \mathrm{CO}_{3}, \mathrm{Na}^{15} \mathrm{NO}_{3}, \mathrm{Na}_{2}{ }^{34} \mathrm{SO}_{4}$ \\
\hline
\end{tabular}

${ }^{1}$ LeKieffre et al. (2017 and unpublished data)

${ }^{2}$ Nomaki et al. (2016) 
Table 2. NanoSIMS measurement settings of Nomaki et al. (2016) and LeKieffre et al. (2017 and unpublished data).

\begin{tabular}{llll}
\hline & ${ }^{13} \mathrm{C} /{ }^{12} \mathrm{C},{ }^{15} \mathrm{~N} /{ }^{14} \mathrm{~N}$ analyses ${ }^{1}$ & ${ }^{15} \mathrm{~N} /{ }^{14} \mathrm{~N}$ analyses ${ }^{2}$ & ${ }^{34} \mathrm{~S} /{ }^{32} \mathrm{~S}$ analysis ${ }^{2}$ \\
\hline Measurement area & $15 \times 15$ or $30 \times 30 \mu \mathrm{m}$ & Typically $8 \times 8$ to $15 \times 15 \mu \mathrm{m}$ & Typically $8 \times 8$ to $16 \times 16 \mu \mathrm{m}$ \\
& $(256 \times 256$ pixels $)$ & $(256 \times 256$ pixels $)$ & $(128 \times 128$ or $256 \times 256$ pixels $)$ \\
Primary beam & about $2 \mathrm{pA} \mathrm{Cs}{ }^{+}$beam & about $1 \mathrm{pA} \mathrm{Cs}{ }^{+}$beam & about $5 \mathrm{pA} \mathrm{Cs}{ }^{+}$beam \\
Primary beam focus size & $120-150 \mathrm{~nm}$ & $<600 \mathrm{~nm}$ & $<1000 \mathrm{~nm}$ \\
Primary beam dwell-time & 5 milliseconds/pixel & $<1$ millisecond/pixel & $<1$ millisecond/pixel \\
Mass resolution & $8000-10000$ at $10 \%$ peak height $>8000$ at $10 \%$ peak height & $>8000$ at $10 \%$ peak height \\
Numbers of sequential image at 1 site & 6 to 10 & Typically 50 & Typically 20
\end{tabular}

${ }^{1}$ LeKieffre et al. (2017 and unpublished data)

${ }^{2}$ Nomaki et al. (2016) 